\title{
Unemployment, Growth and Taxation in Industrial Countries
}

\author{
by \\ Francesco Daveri \\ and \\ Guido Tabellini
(Bocconi University and IGIER) \\ (University of Brescia and IGIER)
}

November 10, 1997

This paper is part of a World Bank research project on growth and labor markets. We thank the World Bank for financial support. We are grateful for comments to Giuseppe Bertola, Tito Boeri, Mike Burda, Carlo Favero, Andrea Ichino, Otmar Issing, John Kennan, Francesco Lippi, Alessandro Missale, Stephen Nickell, Alessandro Penati, Torsten Persson, Martin Rama and Xavier Sala-i-Martin, as well as to the participants in the 1997 NBER Summer Institute, the 1997 EEA Meeting, the ESF Conference 'Growth in closed and open economies', the European Summer Institute in Berlin, the conference on "Dynamic Models of Economic Policy" at the University of Rochester, and in seminars at the IMF, Paris, ULB, Brescia, IGIER, and Trento. We are also indebted to Anna Fruttero for excellent research assistance, and to Gian Maria Milesi-Ferretti and Gilles Saint-Paul for giving us their data on tax rates and unemployment benefits. 


\section{Introduction}

The most pressing economic problem in Europe today is the apparently endless surge in unemployment. Other industrial countries have also seen an increase in unemployment over time, though to a smaller extent. To the layman, the upward trend in unemployment is related to the slowdown in economic growth, which is also apparent in most industrial countries and in particular in Europe. Both trends are illustrated in Table 1 and Figure 1. Given the long time periods involved, these two trends are not simply the result of business cycle fluctuations, but reflect long run tendencies. The observed negative relation between long run growth and unemployment is at odds with the economist's shared opinion that the natural rate of unemployment is invariant to productivity growth ${ }^{1}$. Despite a very large literature on growth and unemployment, few papers have jointly studied these two phenomena; none has made a systematic effort to come to grips with the mentioned evidence from industrial countries ${ }^{2}$.

This paper argues that the layman's view is correct and compatible with the economist's view. The observed increase in unemployment and the slowdown in economic growth are related, because they stem from a common cause: an excessively high cost of labor. If labor markets are non-competitive, an exogenous and permanent increase in labor costs has two effects: on the one hand, it reduces labor demand, and thus creates unemployment. On the other hand, as firms substitute capital for labor, the marginal product of capital falls; over long periods of time, this in turn diminishes the incentive to accumulate and thus to grow. Then high unemployment is associated with slow growth. Whether the growth slowdown is permanent or transitory depends on the productive technology. In the framework of endogenous growth theory, this can be a permanent effect, while in the neoclassical model of growth this is a transitory

\footnotetext{
1 This result was obtained by Phelps (1968) and more recently restated in Gordon (1997) and Blanchard (1996, ch.25).

${ }^{2}$ The main issues on European unemployment are recently surveyed in Bean (1994), Alogoskoufis et alii (1995), and the OECD Jobs Studies (1994), but little regard is given there to the growth-unemployment link. Search theory, as summarized in Pissarides (1990, ch.2), has made a theoretical case that growth and unemployment are negatively related in the long run. As exogenous technical change drives productivity up, the rate of return on the creation of job vacancies rises, which accelerates the exit rate from unemployment. Aghion and Howitt (1994) allow for search unemployment in their model of growth through creative destruction. More rapid growth shortens the average length of a given job match, thus increasing job separation and reducing job finding rates. Depending on whether the 'capitalization effect' or the 'creative destruction effect' prevail, the growth-unemployment relation may be negative or positive.
} 
phenomenon $^{3}$. The surge in unemployment, on the other hand, is permanent. Exogenous or endogenous labor productivity growth feeds into higher real wages and unemployment subsidies in equilibrium. Thus productivity growth does not affect the natural rate of unemployment, as argued by Phelps. There is nothing very profound nor very surprising in these arguments. Yet, often the simplest explanations are also the best explanations.

In Europe, labor costs have gone up for many reasons, but one is particularly easy to identify: higher taxes on labor. As shown in Table 2, labor taxes have gone up in almost every country and in almost every decade. If labor markets are competitive, the small elasticity of individual labor supply implies that the burden of a tax on labor income is borne almost entirely by the worker, with little effect on unemployment and the capital-labor ratio. But if workers are organized in monopolistic unions, they can succeed in shifting the burden of labor taxes onto firms. In this case, a rise in labor taxes permanently increases unemployment, and it (permanently or temporarily) increases the capital-labor ratio, reduces the rate of return on capital and slows down economic growth.

This paper formulates a simple OLG growth model with a unionized labor market, which makes this argument more precise. The theory is then used as a basis for identification, and its predictions are investigated against the evidence of a panel of 14 OECD countries over the period 1965-1991, contrasting Europe and other industrial countries.

The variety in labor market institutions across countries is useful, because the negative effect of labor taxation on employment and growth is expected to be much more pronounced in Europe, where labor markets are clearly dominated by large trade unions. This is what we find in the data on labor taxes and unemployment depicted in Figures 2 and 3. The difference between Europe and the other industrial countries is striking: the high positive correlation between tax rates on labor income and unemployment is clearly a European phenomenon, not present elsewhere.

This difference between Europe and the rest of the industrial world is also reflected in the behavior of the capital-labor ratio. The IMF estimates that between 1970 and 1995 the capital-labor ratio more than doubled in the European Union, whereas it

\footnotetext{
See also Mortensen and Pissarides (1997).

${ }^{3}$ Furuya (1995) has recently studied the implications of efficiency wages in a Solow growth model, showing that a negative relation may arise along the transition to the steady state.
} 
only rose by $25 \%$ in the US. The Summers-Heston data on capital stocks deliver a similar message. Between 1965-70 and 1986-91 the average capital stock per employee increased by approximately 65\%, $70 \%$ and $100 \%$ in the US, Australia and Canada respectively. In the same period, the cumulative growth of capital per employee reached $130 \%, 150 \%, 175 \%$ and $280 \%$ in Italy, France, Germany and Spain, even though their growth of per-capita GDP was very similar to that of the Anglo-Saxon countries. ${ }^{4}$

A crucial step in our argument is that the effect of higher labor taxes on unemployment is due to higher real wages. This prediction is also strongly supported by the data: in the paper we show that higher tax rates on labor are indeed shifted onto higher gross wages in Europe, but not in the other OECD countries. Finally, the paper shows that, as expected, the capital-labor ratio is strongly and robustly correlated with the increase in real wages.

The policy implications of this view are straightforward but extremely relevant. In a world with monopolistic trade unions, labor taxes can be as distorting and harmful to growth as capital taxes. According to the data, the effective tax rate on capital in Europe was on average equal to $22.7 \%$ in $1965-75$ and reached $32.9 \%$ in $1976-91$. In the same group of countries, the average effective tax rate on labor rose from $31.1 \%$ on average in $1965-75$ to $40.5 \%$ in $1976-91$, reaching $43.2 \%$ in 1986-91. Moderating the overall level of taxation and mostly of taxes on labor is one of the main challenges currently faced by the European Union.

Our empirical results provide a quantitative evaluation of how costly higher labor taxes have been in Europe, in terms of reduced growth and higher unemployment. In spite of the variety of methods of estimation and instruments we used, all of our estimates produce similar quantitative answers. The rise of almost 10 percentage points in the rate of effective labor taxes can account for a 4 percentage points increase in European unemployment. Moreover, the rise of labor taxes is also associated to $a$ reduction of the EU growth rate of about 0.4 percentage points a year - a respectable loss indeed if considered over a time horizon of about fifteen years, and about one third of the observed reduction in growth between 1965-75 and 1976-91. In contrast, the

\footnotetext{
${ }^{4}$ As noted by Blanchard (1997), the labor share of income fell in continental Europe but not in other industrial countries over this same time period. This paper does not attempt to address this other stylized fact, even though it is not inconsistent with our proposed explanation of the European unemployment problem. An increase in labor taxes causing higher unemployment can also reduce the labor share of
} 
equally sizable rise in capital tax rates (about 10 percentage points between 1965-75 and 1976-91) appears to have slowed down annual growth rates in the EU by a bare $0.06 \%$ a year. But while the small effect of capital taxes on growth is a finding already known to growth theorists ${ }^{5}$, the sizable growth effect of labor taxes is novel and lends itself to be further discussed with reference to other periods and groups of countries.

If the explanation is so simple and straightforward, why have so few papers pointed out that labor taxes are a key determinant of European unemployment ? As reported by Blanchard and Katz (1996, p.24), 'the role of taxes was a main focus of the multi-country study organized by Richard Layard and Steve Nickell in the mid-1980s. (...) Yet, the cross-sectional evidence within Europe does not reveal much correlation between tax rates and unemployment rates, nor between changes in tax rates and changes in unemployment'. Our study confirms these previous findings in the cross-section of 14 OECD countries. Cross-sectional variations in unemployment rates tend to be dominated by fixed effects at the country level. This is not too surprising: as documented for instance by Nickell (1997), labor market legislation differs markedly across countries, and such legislation did not change much after the late 1960s or early 1970s. Labor taxes significantly predict how unemployment changes over time within each country, however. Moreover, this correlation is strong and evident among the highly unionized countries of Continental Europe, and much less so in countries with competitive labor markets, and in the Scandinavian countries with highly centralized trade unions. Thus, the correlation between labor taxes and unemployment is only captured by simultaneously exploiting the time series and cross-country variations of the data, and by distinguishing among countries on the basis of their labor market institutions. This distinction as well as the emphasis on time series (as opposed to cross country) correlations was missing in many previous studies on European unemployment.

Some of the ideas in this paper are clearly related to Bruno and Sachs (1985) and Phelps (1994). The theoretical analysis in both books was not cast in terms of modern growth theory, however. They had more ambitious goals, and their analysis also focused on business cycle phenomena and on international linkages. The empirical analysis was also different from that of this paper, in the set of economic variables considered and

\footnotetext{
income if the elasticity of substitution between capital and labor is sufficiently high.

${ }^{5}$ As conjectured by Harberger (1964), Lucas (1990) calculates that eliminating capital taxes in a revenueneutral way would produce no change in the long-run growth rate of the US economy.
} 
because countries were not grouped according to their labor market institutions. Finally, Alesina and Perotti (1994) found a relation between labor taxes and unit labor costs in a sample of OECD countries, using data on tax rates different from ours, but also discriminating between countries on the basis of the role of trade unions. Alesina and Perotti (1994) mainly focus on competitiveness, but the approach of our paper is consistent with many of their results. ${ }^{6}$

The paper outline is as follows. Section 2 presents the model. In equilibrium, growth and employment are decreasing functions of labor taxes. Section 3 looks at the evidence. Section 4 concludes the paper.

\section{The Theory}

In this section, we present an OLG growth model where equilibrium unemployment is caused by monopolistic trade unions. Depending on the assumptions about technology, growth could either be endogenous, or just a feature of the transition to the steady state. In both cases, there is a negative relation between unemployment, on the one hand, and the rate of return on capital and the growth rate, on the other. This relation could be permanent or transitory, depending on the productive technology. The OLG structure is not central to our results and the seemingly myopic behavior of the monopoly union, which only cares about today members' incomes, is a simple shortcut for a more general setting where the union is infinitely lived but cannot commit to future courses of action.

\subsection{A Simple Model}

Consider a two-period overlapping generations economy with constant population and closed to international trade. Individuals are non-altruistic and have a homothetic and separable utility function defined over consumption when young and old, $c$ and $d$ respectively.

Only young individuals can work. They can be employed or unemployed. If employed, they earn wage income net of taxes, $w\left(1-\tau^{L}\right)$, where $\tau^{L}$ is the labor income tax rate. If unemployed, they earn an unemployment subsidy, $s$, which is not taxable. ${ }^{7}$

\footnotetext{
${ }^{6}$ Other more specific papers investigating the empirical evidence on wages, unemployment and taxation are Padoa Schioppa (1990), Tyrvainen (1994), and Tullio (1987). Bean (1994) and OECD (1994) surveyed this strand of literature.

${ }^{7}$ Alternatively, a slight modification of the model could lead to an alternative interpretation : $s$ could
} 
Individual labor supply is set equal to one. A given fraction $\lambda \leq 1$ of young individuals belongs to a trade union. We treat union membership as parametric, whereas the number of employed individuals is endogenous. If the number of union members is larger than the number of employed individuals, then we assume that all employed individuals are also union members ${ }^{8}$. Old individuals earn a return (net of taxes) of $\left[1+\left(1-\tau^{K}\right) r\right]$ on their investments when young, where $\tau^{K}$ is the tax rate on capital, and $r$ is the rate of return on capital. Physical capital is the only outside asset and, for simplicity, it is subject to no depreciation; savings by the young are denoted by $k$ '.

Under these assumptions, the individual budget constraints of a young and old individual respectively are :

$$
\begin{gathered}
y^{i}=k^{\prime i}+c^{i} \\
{\left[1+\left(1-\tau^{K}\right) r\right] k^{\prime i}=d^{i}}
\end{gathered}
$$

where $i$ stands for either employed (E) or unemployed (U), and $y^{E}=w\left(1-\tau^{L}\right), y^{U}=s$. By homotheticity, the amount saved by a young individual with income $y^{i}$ is :

$$
k^{, i}=y^{i} F\left[r\left(1-\tau^{K}\right)\right]
$$

where $F($.$) is a known function, whose properties depend on underlying preferences. We$ assume $F($.$) to be increasing (i.e. the substitution effect prevails over the income effect).$

Let $l \leq 1$ be the fraction of employed individuals in the (young) population, and $k$ be the average holdings of capital by those currently old. Then we can write the government budget constraint in per capita terms as:

$$
\tau^{K} r k+\tau^{L} w l=\gamma+(1-l) s
$$

where $\gamma$ denotes per capita government consumption. In a growing economy, fiscal policy variables also tend to grow over time. To preserve balanced growth, we assume that both per capita public consumption and unemployment subsidies are given linear functions of average per capita income $y$ (to be defined below). Thus: $\gamma=\delta y ; s=\sigma y$. In the OECD data analyzed in section 3, the replacement ratio (i.e. the parameter $\sigma$ ) is constant or increasing over time, but certainly not decreasing. The parameters $\sigma$ and $\delta$, together with the tax rates, are the policy variables controlled by the government. To simplify the

denote the wage rate in the underground economy or in a non-unionized sector where taxes can be evaded more easily. In most countries, unemployment subsidies are part of taxable income, but the effective tax rate is much lower both because of deductions on low income households and of payroll taxes on employed workers. 
comparative statics, we assume that the parameter $\delta$ is adjusted by the government whenever tax rates change, so as to keep $\sigma$ constant.

Average capital per worker evolves over time according to the following law of motion:

$$
k^{\prime}=l k^{\prime E}+(1-l) k^{\prime U}
$$

where $k^{\prime}$ denotes average holdings of capital in the next period.

Production takes place in a large number of identical competitive firms, endowed with the following technology:

$$
y=\phi(k) l^{1-\alpha}
$$

where $y$ is the level of output (or income) divided by the labor force $N, l$ is the employment rate, $k$ is capital at the beginning of the period also divided by $N$, and $\phi($.$) is$ a concave and increasing function to be specified in subsection 2.3 below. Thus, we restrict labor demand elasticity to be constant. This simplifies the analysis in that equilibrium employment remains constant over time. This formulation encompasses different growth models, such as the neoclassical growth model and a variety of endogenous growth models, depending on the specification of the function $\phi($.$) . All$ these models have the similar implications for the equilibrium, except on one dimension, namely how lasting are the effect of taxes on growth and investment: whereas such effects are temporary in the neoclassical growth model, they are permanent in a variety of endogenous growth formulations. We discuss these issues in subsection 2.3 below.

Competitive firms hire labor and capital up to the point where the respective perceived marginal product equals the relevant input price. In particular, inverting the firms first order conditions with respect to labor, we obtain that labor demand (i.e. the employment rate) is a function $L(k, w)$ defined by:

$$
l=[(1-\alpha) \phi(k) / w]^{1 / \alpha} \equiv L(k, w)
$$

Similarly, the perceived rate of return to the firm own capital is the partial derivative of the right hand side of (6) with respect to $k$, namely:

$$
r=\phi_{k}(k) l^{1-\alpha}
$$

Thus, quite intuitively, for any given value of $k$ the rate of return on capital is an increasing function of the employment rate: when existing capital is combined with

\footnotetext{
8 This assumption simplifies the exposition but is not central to our results.
} 
more labor, it is more productive. Naturally, the stock of capital is endogenous too, and how that evolves over time depends on the assumptions about $\phi($.$) .$

\subsection{Labor Market Equilibrium}

Wages are set by monopolistic trade unions. We assume that the union is large enough to be able to set wages, but small enough to take fiscal policy variables and the interest rate as given. Thus, unions operate at the firm or sector level. Under this assumption, the welfare of the current old cannot be affected by the union. Moreover, the union affects the welfare of the current young only through their current income. Thus, the union faces a static optimization problem. To simplify the analysis, we neglect risk aversion and postulate that unions maximize the expected income (rather than the expected utility) of their young members, subject to the labor demand function (7). That is, in each period the union sets wages so as to maximize in an utilitarian fashion:

$$
\frac{L(k, w)}{\lambda} w\left(1-\tau^{L}\right)+\frac{\lambda-L(k, w)}{\lambda} s
$$

The union's optimization problem in equation (9) generalizes to an infinite horizon setting, where the union cannot commit to future policies. Under our assumption that all employed individuals belong to a union, the ratio $l / \lambda$ is the fraction of union members that finds a job. Thus, the first term in (9) is the net wage times the probability of finding a job, while the second term is the unemployment subsidy times the probability of being unemployed. ${ }^{9}$

Given our production function, the optimal net wage for the union is a constant mark-up over the unemployment subsidy . Specifically, maximization of (9) with respect to the wage and taking the subsidy $s$ as given implies :

$$
w=\frac{s}{(1-\alpha)\left(1-\tau^{L}\right)}
$$

This formulation of the trade union wage setting problem is standard. Firms have the right to hire as many workers as dictated by the perceived labor demand curve, at the wage level preset by the monopolistic union. In general, this implies some equilibrium

\footnotetext{
${ }^{9}$ The assumption that trade unions maximize expected income (and not expected utility) of their members can also be interpreted as saying that there is an insurance scheme within the union against the risk of being unemployed.
} 
unemployment. We do not try to address the known weaknesses of union models ${ }^{10}$ : anyway, the main conclusions of our model generalize to other labor market imperfections. ${ }^{11}$ The key feature of labor markets we are committed to discuss is that labor market institutions at the country level play a role in determining whether a relation between labor taxes, unemployment and growth shows up in the data. This feature is parsimoniously embodied in our model.

Given the equilibrium wage rate, it is straightforward to compute equilibrium employment by combining (4), (7) and (10), to obtain :

$$
l^{*}=\left[(1-\alpha)^{2}\left(1-\tau^{L}\right) / \sigma\right]
$$

where a '*' denotes equilibrium variables and $\sigma$ is the replacement rate in the unemployment subsidy - recall our earlier assumption that $s=\sigma y$. Thus, as expected, a higher tax rate is met by a higher gross wage, which in turn forces firms to cut employment. Moreover, a higher replacement rate (a higher $\sigma$ ) also reduces employment, because it leads to a proportionate increase in gross wages. It is easy to show that in equilibrium there is a positive rate of unemployment (that $l^{*}<1$ ). ${ }^{12}$ Finally, for a constant tax rate and a constant $\sigma$, equilibrium employment is also constant. This is a special feature due to the production function we have adopted.

\subsection{Equilibrium Growth}

We can now combine all the pieces to compute the equilibrium growth rate. By (5) and (3), the new average capital stock evolves according to:

$$
k^{\prime}=F\left[r\left(1-\tau^{K}\right)\right]\left[l w\left(1-\tau^{L}\right)+(1-l) s\right]
$$

Hence, by (8), (10) and (12), the equilibrium growth rate, $g *(k)$, is:

$$
1+g *(k) \equiv k^{\prime} / k=F\left[\phi_{k}(k) l^{* 1-\alpha}\left(1-\tau^{k}\right)\right]\left[1+l * \frac{\alpha}{1-\alpha}\right] \sigma l *^{1-\alpha} \frac{\phi(k)}{k}
$$

Thus, at any moment in time and for any given initial capital stock, equilibrium growth is

\footnotetext{
${ }^{10}$ To name a few, one may ask where the market power of unions originates from, why so little wage underbidding on the part of the unemployed is observed, and why unemployment exists even when unions are absent. Lindbeck (1993) summarizes many of these questions.

${ }^{11}$ Furuya (1995) derived implications reminiscent of ours in a model with Solow technology and efficiency wages.

${ }^{12} \mathrm{We}$ assume here for convenience that $l^{*}<\lambda$. If $\lambda$ is sufficiently small that $l^{*}=\lambda$, then from then on it remains true that $l=\lambda$ for all parameter values that would otherwise increase employment, and the wage rate is no longer determined by (10) but instead by (7) together with the condition that $l=\lambda$.
} 
higher the greater is the employment rate. The effect of employment on growth occurs through two distinct channels. First, from equation (8), higher employment increases the marginal product of capital, as captured by the term $l^{1-\alpha} \phi_{k}(k)$, and this in turn induces more savings by the young. Second, higher employment increases the average income of young individuals, which, in turn, in a life-cycle model, leads to more savings. This is captured by the term $l^{l-\alpha} \phi(k) / k$ at the very end of the right hand side of (13). The second channel is a special feature of an overlapping generations economy in which individuals only work when young, and it would disappear if work were uniformly spread throughout one's lifetime. But the first channel is very robust and intuitive. Higher employment implies a lower capital-labor ratio, and hence a more productive capital stock; this in turn fosters investment and hence stimulates growth.

How exactly equilibrium growth varies over time depends on the functional form of $\phi(k)$. Take a Cobb-Douglas production function, as in Diamond (1965), where: $\phi(k)=B k^{\alpha}$, so that $\phi_{k}(k)=\alpha B k^{\alpha-1}$ and $\phi(k) / k=B k^{\alpha-1}$, where $B>0$ is a constant parameter. Then, the growth rate equation (13) specializes to:

$$
1+g *(k) \equiv k^{\prime} / k=F\left[\alpha B k^{\alpha-1} l^{*^{1-\alpha}}\left(1-\tau^{k}\right)\right]\left[1+l * \frac{\alpha}{1-\alpha}\right] \sigma l^{*^{1-\alpha}} B k^{\alpha-1}
$$

Here $g^{*}(k)$ converges asymptotically to 0 (the right hand side of (14) converges to 1 ), as $k$ converges to the steady state. In this neoclassical set up, an exogenous reduction in employment has a negative but transitory effect on growth. The fall in employment induces firms to reduce investment. If $\phi($.$) is concave, the smaller capital stock increases$ the rate of return on capital until the growth effect vanishes and the economy is back to a lower steady state level of output.

At the opposite extreme, suppose that $\phi(k)=A k$, so that $\phi_{k}(k)=A=\phi(k) / k$, where $A>0$ is a constant parameter. The corresponding growth rate is:

$$
1+g *(k) \equiv k^{\prime} / k=F\left[A l^{1-\alpha}\left(1-\tau^{k}\right)\right]\left[1+l * \frac{\alpha}{1-\alpha}\right] \sigma l *^{1-\alpha} A
$$

Here it is easy to see that if $A$ is sufficiently large, then the equilibrium growth rate is positive and constant over time, and it is permanently affected by changes in the employment rate. As employment is reduced, the marginal product of capital falls. Firms scale down investment, but here the marginal product of capital is not affected by this lower investment rate. Hence the growth effect is permanent. Models with $A K$ 
technologies have been extensively studied in the endogenous growth literature, and the technological assumptions that give rise to them are well known. A specific and simple example is Romer (1986, 1989), where each firm faces a Cobb-Douglas production function in capital and labor with constant returns to scale, but there is an externality in average capital. To generate the result that growth is permanently affected by the employment rate, so that in equilibrium $\phi(k)=A k$, the externality should be defined over capital per worker (i.e. per member of the labor force) or per individual, rather than over capital per employee. ${ }^{13}$ A second and widely studied example concerns economies with endogenous technological progress and imperfect competition, such as in Romer (1987), (1990), or Bertola (1993). Here too, the equilibrium aggregate production function for the final good is linear in average capital per individual, and changes in the economywide employment rate have a permanent growth effect.

Intermediate cases are also possible. Take for instance the production function suggested by Jones and Manuelli (1990), where $\phi(k)=A k+B k^{\alpha}$. Here $\phi_{k}(k)=A+B k^{\alpha-1}$ and $\phi(k) / k=A+\alpha B k^{\alpha-1}$. Thus, equilibrium growth is not constant at any instant, but only asymptotically, as $k$ approaches infinity. Here changes in the employment rate have both permanent and transitory effects on equilibrium growth. Moreover, the model now predicts conditional convergence in growth rates: poorer countries experience temporarily higher growth rates.

Summarizing, the - temporary or permanent - link between employment and output growth is a key feature of many growth models. Oddly enough, this feature, which plays such a critical role in business cycle analysis, has been neglected in the theory of economic growth, because typical growth models assume competitive labor markets and full employment. But once employment is regarded as endogenous, the variables determining employment also affect growth, with important policy implications.

${ }^{13}$ Specifically, we can write the production function faced by each firm as:

$$
Q=A k^{1-\alpha} K^{\alpha} L^{1-\alpha}
$$

where $Q$ denotes total output produced in a typical firm, $L$ and $K$ denote the inputs of labor and capital hired in that firm and $k$ is average capital per worker (i.e. member of the labor force). Dividing both terms by $N$ and simplifying, we obtain that in equilibrium average output can be written as in (6), with $\phi(k)=A k$. Note however that here $\phi_{k}(k)=\alpha A<A$ because of the externality. The actual presence of external effects in production is a debated issue in macroeconomics. Caballero and Lyons (1992) provide evidence in favor of the presence of production externalities, of a smaller size than 0.66 (the available best guess for $1-\alpha$ ), however. Other studies reach opposite (Burnside, 1996) or mixed (Basu and Fernald, 1995) conclusions. 
Consider in particular the consequences of higher tax rates. ${ }^{14}$ To focus on one policy intervention at a time, we assume that the government consumption share (the parameter $\delta$ defined above) is appropriately adjusted so as to keep the government budget balanced at any instant of time. Then a higher capital tax rate, $\tau^{K}$, reduces the net rate of return on investment and equilibrium growth. ${ }^{15}$ This growth-reducing effect motivates the common view that capital taxes are highly distorting and, from an efficiency point of view, should be avoided as much as possible (see for instance Rebelo (1991)). But in our model, labor taxes have a similar effect: by (11) and (13), a higher $\tau^{L}$ reduces equilibrium employment and, through this channel, it also reduces growth. Which tax rate is more harmful for growth is ambiguous, and depends on parameter values. But if tax rates are the same at the outset, in this model a rise in labor taxes is unambiguously costlier to growth than a rise in capital taxes. ${ }^{16}$ Naturally, taxes on labor also increase unemployment.

\section{$\underline{2.4 \text { Extensions }}$}

Our barebones model can be extended in several ways. Some of them can be easily adressed, others would require more careful work. We discuss here some of the more important and fruitful extensions.

\subsubsection{Human Capital Accumulation}

One might wonder what happens to our results if human - rather than physical -capital is the actual engine of growth. In a nutshell, the learning enabled by the process of human capital accumulation opens up another route for labor taxes to directly affect growth. This has already been studied by Stokey and Rebelo (1995) and Jones, Manuelli and Rossi (1993), under the assumption of competitive labor markets. One implication not fully developed in these studies - and instead discussed by Lucas (1993) and Mendoza, Milesi-Ferretti and Asea (1996) - is that this effect crucially depends on whether human

\footnotetext{
${ }^{14}$ Following the tradition of the growth literature, we discuss the effects of tax rates on growth disregarding the issue of their timing and treating all changes in tax rates as permanent and unexpected.

15 Exceptions are those models, like Lucas (1988), where growth is due to human capital accumulation and physical capital does not enter the production function of human capital. Models of this kind are discussed at some length in section 2.4.1.

${ }^{16}$ The intuition underlying this result is as follows. If tax rates are the same at the beginning, the effects of higher taxes on the rate of return on capital are approximately equal. But the adverse growth effects of the tax on labor are augmented by their negative impact on savings.
} 
capital accumulation takes place through formal or informal channels.

If human capital accumulation occurs formally through, say, schooling or formal training, then employment today reduces the amount of time potentially devoted to human capital accumulation. The positive growth effect of increased employment on the marginal productivity of both types of capital is thus counteracted by this negative effect. The overall effect of unemployment on the growth rate becomes possibly nil.

If instead human capital is accumulated as a result of learning on the job, then working today causes one to be more productive tomorrow through a standard learningby-doing effect (in our model, this would have to be an intergenerational effect). In this case, the negative link between unemployment and growth would be reinforced rather than weakened. If labor markets are competitive, then the effect of labor taxes on growth is the same across countries. But with non-competitive labor markets, the effects of labor taxes on growth differ across countries, and are more pronounced in the presence of monopolistic unions.

A simple formalization of on-the-job learning compatible with our model draws on Lucas (1993). Suppose that human capital is unintentionally accumulated on the job according to the following linear law of motion:

$$
h^{\prime}=A l h
$$

where $h$ is the amount of human capital (ability) a young is endowed with at birth, which is then bequeathed to the next generation of young $\left(h^{\prime}\right)$. In turn, human capital enters the production function of final goods, augmenting labor effort as follows:

$$
y=B k^{\alpha}(l h)^{1-\alpha}
$$

It can be readily shown that we are in an ' $A k$ ' economy where all level variables, except for $l$, are now linear in $h$ in equilibrium. From the equation for human capital accumulation, the equilibrium growth rate of the economy is clearly an increasing function of the employment rate ${ }^{17}$. In turn, the employment rate is constant and depends on the usual fiscal and technology parameters.

\subsubsection{Large and Centralized Trade Unions}

Union models tend to blame the "excessive" size or power of unions for the existence of

\footnotetext{
${ }^{17}$ The equality between the growth rates of human and physical capital is guaranteed by instantaneous variations in the ratio between the two stocks of capital, like in Barro and Sala-i-Martin (1995, ch.5).
} 
unemployment. Monopoly unions do not take the wage as given, but push for higher wages at the firm or sector level. This drives firms to ration employment along their labor demand curve in order to maximize profits. As emphasized earlier, our basic model is no exception to this practice. Our trade union is large enough to set wages, but not large enough to negotiate over fiscal policy with the government.

Along the lines developed by Calmfors and Driffill (1988) and Summers, Gruber and Vergara (1993), however, one may conjecture that if wage setting is centralized and workers are represented by a very large trade union, then they are likely to develop a more moderate attitude in negotiations. Centralized and large unions would internalize the budgetary implications of unemployment subsidies, as well the adverse consequences of an economy-wide drop in the capital-labor ratio, to a greater extent than medium-sized unions that bargain in a decentralized fashion at the firm or sector level. Wages would thus be set to a lower level than in the monopoly union model. Addressing this issue satisfactorily would require a more realistic model of union behavior - something which the existing literature has yet to settle on. But these considerations suggests that, when looking at the empirical determinants of unemployment, countries might be partitioned in more than just two groups (i.e competitive or unionized labor markets), so as to allow for different patterns of wage negotiations by trade unions.

\subsubsection{Open Economies and International Capital Mobility}

In a small open economy with international capital mobility and only one good, the capital-labor ratio and hence the gross real wage is pinned down in the long run by the condition that the rates of return on domestic and foreign investment are the same. Some economists have argued that, for this reason, labor taxes are not distorting in a small open economy, because the tax burden is entirely borne by labor (Nickell (1997)). This view neglects an important timing issue, however. International capital mobility equalizes the expected rate of return. This in turn depends on future, rather than current, wages. When unions set wages, they take existing capital as given. Therefore, wage setting behavior is not affected by the extent of capital mobility. This is literally true in our overlapping generations economy. It would continue to be true in a richer infinite horizon economy, as a time-consistency argument would force the union to take future wages as given when setting current wages. This is a version of the well known capital-levy problem, 
extensively studied in public finance with regard to capital taxation (see Persson and Tabellini (1997) and, for an application to union behavior, van der Ploeg (1987)). Hence, even in a small open economy model with rational monopolistic trade unions, higher labor taxes would be shifted onto higher wages in the short run.

Opening up the economy to capital mobility, however, would affect the long run consequences of these higher labor taxes. Now capital would leave the country, on the expectation of higher future wages. In the new long run equilibrium, the capital-labor ratio would return towards a level consistent with the equalization of domestic and foreign rates of return. But the adjustment to this new equilibrium would entail both capital outflows as well as increased unemployment. Modelling precisely this would require additional features to ensure the existence of equilibrium. ${ }^{18}$ Moreover, a satisfactory model would entail more than one good. Pursuing this extension is therefore beyond the scope of this paper. But the general point we want to stress is that opening up the economy would not eliminate the distorting effects of labor taxes. On the contrary, new and potentially worse distortions would arise. Alesina and Perotti (1994) address some of these issues in a related framework.

\subsubsection{Employment and Growth in Developing Countries}

In our model, those that are not employed in the unionized sector remain unemployed. The channel through which unemployment is damaging for growth hinges on the noncompetitive nature of the labor market. This may be appropriate for industrial countries where trade unions are usually large and powerful organizations. In developing countries, however, a large fraction of the working population is employed in the informal sector, where labor is competitively supplied. Wage underbidding on the part of the competitive fringe of informal workers is likely to bring wage rates down to competitive levels in these countries. This tends to restrict the scope for applying our basic model.

The employment-growth link may apply to developing countries as well, however, though the driving forces are not the same. Suppose, following Young (1993), that the economy features a dual structure. Then modern sector firms face the same production function as above and negotiate wage and employment with monopolistic

\footnotetext{
${ }^{18}$ In particular, we would need a model in which higher unemployment moderates somewhat the union demands, or in which capital outflows are not costless.
} 
trade unions, while firms in the backward sector face competitive labor markets and only use labor inputs (i.e. $s$ is the wage in this other sector). In a companion paper under preparation, joint with Martin Rama, we show that, as capital grows, so does employment in the unionized sector. The reason is that now the wage in the unionized factor remains fixed with a mark up over the constant subsistence wage, $s$. Thus, the term $w / k$ falls over time, and labor demand in the unionized sector grows as labor becomes more productive, since capital continues to grow. Eventually, all employment is suck in the unionized sector. At that point, the economy behaves as in the model of subsections 2.1-2.3 above. As documented by Young (1993), this pattern of development is very consistent with the evidence of a number of countries in East Asia.

\subsection{Empirical Implications}

The theoretical results summarized in the previous sections can be contrasted with the time series and cross section evidence of a panel of industrial countries. Our main goal is to test the following theoretical propositions: (i) In countries with strong but decentralized trade unions, higher labor taxes lead to higher unemployment and higher gross real wages. (ii) A higher cost of labor per employee induces firms to substitute capital for labor, in every country. (iii) This in turn reduces the return to capital accumulation, slowing down investment and hence growth.

Our strategy is to take the model seriously as a basis for identification. The theory helps because it has a simple recursive structure. In particular, we consider the equilibrium conditions for employment and growth in (11) and (13), as well as the wage setting and labor demand equations, (10) and (7) respectively. We are not committed to the precise functional forms of these expressions, however. In particular, we do not attempt to discriminate between endogenous versus exogenous growth models, and thus we do not address the issue of whether the correlation between employment and growth is permanent or temporary.

Consider the equilibrium employment equation first, and let $u_{i t}=1-l_{i t}$ be the unemployment rate in country $i$ and period $t$. Taking a linear approximation of (11), unemployment can be written as a function:

$$
u_{i t}=\beta_{0}+\beta_{1} \tau^{L}{ }_{i t}+\beta_{2} \sigma_{i t}+\beta_{3} x_{i t}+v^{u}{ }_{i t}
$$

where $x_{i t}$ is a vector of other observable determinants of unemployment besides the labor 
tax rate $\tau^{L}$ and the replacement rate $\sigma$, not captured by our simple theoretical model, and $v_{i t}^{u}$ is an unobserved error term. In the empirical analysis we formulate alternative specifications of the vector $x_{i t}$, such as lagged unemployment, alternative measures of union strength, inflation, various time trends, and the contemporaneous or lagged growth rate of GDP per capita and productivity per worker. We also use more than one measure of unemployment. These alternative specifications are discussed in section 3 .

Our main focus is in the prediction that $\beta_{1}>0$. In particular, we test whether $\beta_{1}$ differs across groups of countries, in accordance to the size and importance of trade unions. If the labor market is competitive and trade unions unimportant, $\beta_{l}$ could be close to 0 . If trade unions play an important role in wage negotiations, but are not so centralized as to internalize all the general equilibrium repercussions of higher wages, we expect $\beta_{l}$ to be large and positive. Finally, $\beta_{l}$ could be smaller again if the trade union is very large and centralized, because of the arguments discussed in the previous subsection and elaborated at length by Calmfors and Driffill (1988). The theory also predicts that $\beta_{2}>0$. It is not clear that the size of this coefficient should also depend on trade union strength and centralization, since even in competitive labor markets higher replacement rates could have a large effect on unemployment through individual search or bargaining attitudes. For this reason, $\beta_{2}$ is constrained to be equal across countries.

Next, consider the determinants of the equilibrium rate of growth in country $i$ and period $t, g_{i t}$. Equation (13) yields the following linear approximation :

$$
g_{i t}=b_{0}+b_{1} \tau^{K}{ }_{i t}+b_{2} u_{i t}+b_{3} z_{i t}+v^{g}{ }_{i t}
$$

where now $z_{i t}$ is a vector of observable variables not all captured by our model, but that nevertheless can be expected to influence economic growth, and $v^{g}{ }_{i t}$ is an unobserved error term. In the empirical analysis, in some specifications we also replace the growth rate of per capita GDP with the share of investment over GDP. ${ }^{19}$ The vector $z$ includes initial per capita income and the secondary enrollment ratio in all growth and investment regressions. The inclusion of initial per-capita income is suggested by the prediction of convergence implied by some formulations of the production function $\phi(k)$, as discussed in the previous subsection. We also ask whether the resuls are robust to alternative specifications, by also including an index of weekly hours actually worked or paid for,

\footnotetext{
${ }^{19}$ This also serves the purpose of checking that the positive effect of the employment rate on growth does not have to do with a movement along the production function.
} 
and the share of population in working age over total population.

Here, the main implication we want to test is that unemployment adversely affects growth and investment: $b_{2}<0$. We restrict this coefficient to be equal across countries. A tax on labor is expected to be costlier to growth and investment in countries with powerful but decentralized unions, because of the induced greater labor market distortion, not because of technological differences across countries. We are also interested in the sign of the tax rate coefficient, $b_{1}$. The basic model predicts that $b_{1}<0$ for all countries equally. The version of the model augmented with human capital accumulation, however, predicts $b_{1}=0$.

Equations (16) and (17) consider the direct impact of taxes and other policy variables on unemployment and growth. But according to the model, this impact occurs through observable channels: on the one hand, higher labor taxes and replacement rates lead to more unemployment because they induce trade unions to demand higher real wages. On the other hand, higher real wages are detrimental for growth because they induce firms to substitute capital for labor, thus raising the capital-labor ratio and reducing the productivity of capital.

Consider the wage setting equation, (10). Taking a log-linear approximation and then differencing, we obtain that the growth rate of gross real wages, $\gamma_{w}$, is an increasing function of the changes in unemployment subsidies and labor taxes. Since unemployment subsidies are assumed to be $s=\sigma y$, we can approximate equation (10) with the following log-linear equation:

$$
\gamma_{w i t}=\delta_{0}+\delta_{1} \Delta \sigma_{i t}+\delta_{2} \Delta \tau^{L}{ }_{i t}+\delta_{3} g_{i t}+\delta_{4} p_{i t}+v^{w}{ }_{i t}
$$

where $\Delta \sigma$ and $\Delta \tau^{L}$ denote the change in the replacement rate and labor tax rate respectively, and $p$ is a vector of other observable variables, such as the unemployment rate, neglected by our simple model but that nevertheless could play an important role in more general bargaining models. In some specification we replace the growth rate of per capita GDP, $g$, with the growth rate of labor productivity. The theory predicts that $\delta_{1}, \delta_{2}$, $\delta_{3}>0$. Our interest is particularly on $\delta_{2}$. As with unemployment, $\delta_{2}$ (but not the other coefficients) is expected to differ across countries, and to be larger where strong but decentralized trade unions shift the tax burden onto firms.

Finally, consider the labor demand equation, (7). It can be expressed in terms of 
the capital labor ratio, $k / l$, desired by the average firm at the going wage rate. Taking logs and then differencing, we obtain that the growth of the capital labor ratio, $\gamma_{k / l}$, can be written as:

$$
\gamma_{k / l i t}=d_{0}+d_{1} \gamma_{w i t}+d_{2} g_{i t}+v^{k / l}{ }_{i t}
$$

where we expect $d_{1}>0>d_{2}$. That is, higher wages lead firms to substitute capital for labor. And higher growth (of output or capital - in the model the two growth rates coincide) leads to an even greater demand for labor, thereby reducing the equilibrium capital-labor ratio.

We now ask whether these predictions are indeed borne out by the data.

\section{The Evidence}

\subsection{The Data}

Our sample is a panel of 14 industrial countries, during the period 1965-91. The sample size is dictated by availability of data on tax rates. To remove the effect of cyclical fluctuations, we average each variable over a five-year period (except for the first and last periods where the average is over six years). Thus, our panel consists of 14 countries and 5 observations per country. We also check our results within the smaller sample (only three observations per country) obtained through 9-year averaging. All data sources are listed in the Data Appendix.

The data on tax rates deserve some special mention. They have been computed from the OECD Revenue Statistics by Mendoza, Milesi-Ferretti and Asea (1996) and filled by ourselves for a few observations, following the methodology of Mendoza, Razin and Tesar (1994). This method calculates effective tax rates as ratios between the revenues collected from a specific source and its taxable income base, reconstructed from national accounting data. This method trades off the disadvantage of giving up the attempt of constructing marginal tax rates - that are relevant for economic analysis - with the advantage of a larger database, since these measures are easier to compute and update. Tables 2 and 3 report these tax rates. The measures of labor tax rates are probably more reliable than those of capital tax rates, because the capital tax base is more likely to be measured with error. There is quite a lot of variation across countries and time in both tax rates. Moreover, as already remarked in the Introduction, in most 
countries both labor and capital taxes show a clear upward trend.

Another issue is how to measure unemployment, and in particular how to treat changes in labor force participation. This issue arises in both the growth and the unemployment equations. Consider the growth equation first, and suppose that the underlying model is the endogenous growth formulation, where the production function $\phi(k)$ reflects an externality, such as in the production function in footnote 13 . If the externality in the production function (6) is defined over capital per worker (that is per member of the labor force), then employment should be scaled to the labor force and the conventional unemployment rate is the appropriate variable to use. If, instead, the externality concerns capital per individual in working age, then the employment rate should be computed by scaling employment to the working age population, and the unemployment rate should be measured as one minus the employment rate. A similar ambiguity arises in the unemployment equation, because some changes in labor force participation are clearly endogenous and affected by, for instance, tax rates and unemployment subsidies, while other changes are clearly exogenous and reflect sociological and cultural factors. In the empirical analysis we mainly rely on conventional measures of unemployment, but we show that all the results are robust to measuring unemployment as one minus the male employment rate. ${ }^{20}$

Table 4 reports the pairwise correlations among the main variables in the whole sample, across countries and over time within each country. Some striking patterns emerge. Consider unemployment first. In all countries, unemployment and labor taxes are strongly positively correlated over time. The correlation tends to be stronger for the countries in continental Europe, as suggested also by Figures $\mathbf{2}$ and $\mathbf{3}$ already mentioned in the introduction. Unemployment is also positively correlated with the replacement rate over time, in most but not all countries. Neither correlation is present across countries, however. One plausible explanation is that there are many institutional differences in the labor markets of different countries, that affect the natural rate of unemployment and that do not vary over time. These other institutional effects could swamp the effect of labor taxes and unemployment subsidies when we look at cross-country correlations.

Next, consider growth and investment. Growth is negatively correlated with both

\footnotetext{
${ }^{20}$ This robustness is a priori not obvious, but these alternative measures of unemployment are highly correlated in our sample: the correlation coefficient between unemployment and one minus the male employment rate is about 0.84 in levels and 0.81 in first differences. See the Appendix for the data sources.
} 
labor and capital tax rates over time; this correlation is a bit weaker than for unemployment. In some years there remains a strong (negative) correlation between growth and capital taxes also across countries. Investment is negatively correlated with the capital tax rate, both over time and across countries.

Unemployment is systematically (negatively) correlated with both growth and investment, as predicted by the theory. The negative correlation between growth and unemployment is only evident within countries, but not across countries. Investment instead is more negatively correlated with unemployment, and this correlation is also present across countries, even though it is weaker than within countries.

Finally, consider real wage growth $\left(\gamma_{w}\right)$. It is positively correlated with the change in the labor tax rate $\left(\Delta \tau^{L}\right)$ over time, but only in some countries, while in others the correlation is negative or absent. Growth of the capital labor ratio $\left(\gamma_{k / l}\right)$ and of real wages are strongly positively correlated, both over time and across countries (the correlation over time is stronger), as expected.

Finally, in the full sample all correlation coefficients have the expected sign, but they are much smaller in magnitude.

Overall, these pair-wise correlations indicate that the time series variation in the data is remarkably in line with the predictions of the theory. In most countries, the rise in labor tax rates over time has been accompanied by a rise in unemployment, and this in turn is associated with a decline in growth and investment. The surge in unemployment is also positively correlated with unemployment benefits. It is instead harder to find a systematic pattern of correlations across countries, except in the case of investment, whose correlations with the other variables are also evident across countries and conform to the theoretical predictions. Finally, there is a strong positive correlation in the growth rates of real wages and of the capital-labor ratio, while the evidence concerning real wages and taxes is more mixed.

\subsection{Labor Market Institutions and Country Groups}

A central implications of the theory is that labor taxes have different effects on unemployment and real wages depending on the role played by trade unions. Labor taxes are expected to have the strongest effect on unemployment if wage negotiations are decentralized and trade unions are powerful but not too large. To test for this implication, 
we partition countries in three groups: the European countries and Australia (EURO), where trade unions play an important role but are decentralized; the Anglo-Saxon countries plus Japan (ANGLO), where labor markets are quite competitive; and the Scandinavian countries (SCAND), where unions are large and centralized. This classification is suggested by several previous studies (Calmfors and Driffill (1988), Bruno and Sachs (1985), Layard, Nickell and Jackman (1991), Cameron (1984)). To decide which country belongs to which group, we classify countries on the basis of available data on trade union density, coverage of collective bargaining, as well as measures of centralization and coordination among unions. ${ }^{21}$ Based on the data in Table 5 and on the mentioned previous studies, the classification of countries within these three groups is quite straightforward, except for four cases. Belgium and the Netherlands could be classified either in EURO or in SCAND. Australia could be classified either in ANGLO or in EURO. And the UK, whose labor market institutions have changed over time, should be classified among EURO for the first three time observations, and in ANGLO for the last two observations. The switch of regime in the UK is quite apparent for both density and coverage data. We experiment with different classifications at the margin, but they do not make much difference for the results. In the end, we break the UK in two different countries depending on periods. Thus, at the cost of some geographical imprecision, EURO includes Australia, Belgium, France, Germany, Italy, the Netherlands, Spain and the first three observations of the UK (covering the 'Labour' years between 1965 and 1980). ANGLO includes Canada, the US, Japan and the last two observations of the UK (the 'Thatcher' years between 1981 and 1991), while SCAND includes Sweden, Norway and Finland. Then, we allow the labor tax coefficient to vary across these groups of countries, by multiplying $\tau^{L}$ by three dummy variables taking a value of unity if the country belongs to the group and zero otherwise. The resulting three variables are labeled $E \tau^{L}, A \tau^{L}, S \tau^{L}$, for the EURO, ANGLO and SCAND groups respectively.

Table 6 summarizes the average behavior of unemployment and growth in these three groups of countries and over time. Naturally, these group averages conceal large variations in individual countries within the same group. Nevertheless, some interesting

\footnotetext{
${ }^{21}$ These data, as well as the country rankings resulting from different previous studies, are extensively discussed in OECD (1997).
} 
patterns emerge. Everywhere, the big surge in unemployment took place between the mid-1970s and the mid-1980s. As is well known, the rise in unemployment is more pronounced in Europe and very mild in Scandinavia. The growth slowdown, on the other hand, is more gradual, and it is similar in all groups of countries. Table 7 summarizes the average behavior of tax rates on labor and capital, and of replacement rates. Tax rates on labor income went up all the time and everywhere. But the increase is more pronounced in Europe and it is also largest in the period between the mid-1970s and mid-1980s. Capital tax rates on average also increased in every period; but here there is more variation across groups of countries and over time. Moreover, the increase in capital tax rates is most pronounced in Scandinavia. Finally, replacement rates on average also increased, particularly in Scandinavia and to a smaller extent in Europe. In the ANGLO group, replacement rates increased during the 1970s but then came down again somewhat during the 1980s. Table 8 summarizes the average behavior of gross real wages and the capital labor ratio (see the data appendix for the sources). Here a somewhat different pattern emerges: both real wage growth and growth in the capital-labor ratio was highest in the first two decades of our sample, for all groups of countries. Moreover, as expected, real wage growth was faster on average in Europe.

Now we turn to multivariate correlations and present the results from our regressions on unemployment, real wages, growth and investment, in turn.

\subsection{Unemployment}

The identification assumptions discussed in subsection 2.5 imply a recursive structure, with unemployment being the first equation of the model. Hence we start with the unemployment equation. The main result of this subsection is that, as predicted by the theory, higher labor taxes are significantly associated with higher unemployment in continental Europe but much less so elsewhere. This holds for a variety of specifications and estimation methods, and in particular even if the recursivity assumption is abandoned.

\subsubsection{Basic specification, alternative estimation methods}

We start by estimating the unemployment equation in levels. Labor market institutions 
are important determinants of unemployment. They are very difficult to measure and differ a lot across countries, but have changed only very slowly over time or not at all since the start of our sample. Hence, the appropriate estimation method is by fixed effects. Thus, we estimate the unemployment equation in levels by OLS, with fifteen country dummies as intercepts (one for each country, except for the UK that we break in two countries so as to distinguish the Labour years from the Thatcher years). Note that fixed effects estimation removes the country mean; hence these estimates reflect the time series (as opposed to cross-country) correlation in the data.

The results are reported in Table 9, column 1. As expected, labor taxes have a strong positive effect on unemployment in the EURO countries. This effect is also positive but smaller in the ANGLO countries, while it is negative but insignificantly different from zero in the Scandinavian countries. The estimated coefficient of the replacement rate, $\sigma$, is also positive and significant, as expected; but, as seen below, this result is not robust across specifications and estimation methods.

Given that unemployment and labor taxes have risen everywhere in the sample, but particularly in Europe, a natural question is whether the level estimates reflect some spurious correlation due to a common trend. Hence we also estimate the equation with all variables measured in first differences (with and without a constant term appended). ${ }^{22}$ Here we drop the fixed effects. Columns 2 and 3 in Table 9 report the results from OLS and GLS regressions for differenced data with a constant term included. OLS estimation in first differences gets rid of spurious correlation problems due to a common trend, but could introduce an $M A(1)$ component in the error term. This is taken care of by GLS estimation, that explicitly allows for a $M A(1)$ structure in the error term.

There is a second, more subtle, possible source of spurious correlation, due to the possible endogeneity of tax rates and unemployment benefits. For instance, a common EU wide shock that increased unemployment could have forced all European countries to also increase labor tax rates to pay for increased unemployment benefits. This potential endogeneity could also reflect our method of measurement, which relies on effective

\footnotetext{
${ }^{22}$ Throughout the paper and unless otherwise noted, a differenced variable is measured as follows: first we compute the five (or six) year average, and then we take the first difference of the average. In the case of the tax rates, data for the period 1960-64 are not available. To avoid losing one observation per country, therefore, we computed the differenced variable for the period 1965-70 (and only for this period) as the difference between the average of the tax rate during 1965-70 and the tax rate in 1965. If tax rates have an upward trend, this underestimates the differenced variable for that period. Tax rates did rise during 1965-
} 
average tax rates rather than statutory rates. We also address this problem below, in other ways. Here, to cope with this possible endogeneity of the right hand side variables, we estimate the differenced unemployment equation by instrumental variables. Column 4 of Table 9 reports such estimates when the instruments for all right hand side variables are the same right hand side variables lagged once in differences and twice in levels. ${ }^{23}$ If the residuals of the unemployment equation are uncorrelated over time, these are pretty good instruments. As discussed below, this estimation method is also appropriate in the presence of measurement error in tax rates, if such error is uncorrelated over time. Yet, since differencing reduces the signal to noise ratio in the variables if they are measured with error, the fit deteriorates. To increase the correlation of the instruments with the regressors, we also include among the instruments a set of time dummies. ${ }^{24}$

No matter how we estimate the differenced regressions, whether by OLS, GLS or IV, the estimated coefficient of $\tau^{L}$ for the ANGLO countries and that of the replacement rate are no longer significantly different from zero. Yet, the estimated coefficient of $\tau^{L}$ in the EURO countries always remains positive and highly significant in all columns. Its size too is quite stable around 0.5, and never drops below 0.37. Furthermore, OLS estimates both in levels and first differences reject the restriction that the coefficients of the labor tax rate are equal for EURO and ANGLO countries (the p-values from Wald tests on that restriction are reported in the last row of each column in the table). The same applies for the coefficients of EURO and SCAND countries. Only IV estimates cannot reject the restriction that the tax coefficients for EURO and ANGLO are equal, presumably because the estimated standard errors are now bigger, since the point estimates for the country groups remain quite different.

Though not reported here, the computed values of the standardized beta

70, but less than in the next years (see also Table 7).

${ }^{23}$ These instruments are uncorrelated with the moving average component of the error term. Thus, the regression coefficients are consistently estimated, even though the estimated standard errors could be biased due to the moving average component. Note that the instruments for $\Delta \tau^{\mathrm{L}}{ }_{\mathrm{t}}$ include $\tau_{\mathrm{t}-2}^{\mathrm{L}}$. This would force us to drop two observations per country, namely those corresponding to 1965-70 and 1971-75. We save one observation by using $\tau^{\mathrm{L}}$ in 1965 , in place of the (unavailable) average of $\tau^{\mathrm{L}}$ during 1960-65, as one of the instruments for $\Delta \tau^{\mathrm{L}}$ in 1971-75.

${ }^{24}$ Removing the time dummies does not change the results. Very similar estimates obtain if the set of instruments is instead defined as: the first difference in replacement rates lagged once; the contemporaneous and lagged change in social security payments as a fraction of GDP, interacted by the country groups EURO, SCAND and ANGLO (source: OECD); and a dummy variable measuring political majorities on a left to right dimension, obtained from Alesina and Roubini (1998), also interacted with the country groups EURO, SCAND and ANGLO. 
coefficients suggest that labor taxes are not only statistically significant, but also economically relevant determinants of unemployment: their standardized coefficient is always the largest of any regressor. ${ }^{25}$

Finally, the test diagnostics for the residuals from all regressions usually cannot reject the assumptions of normality and no serial correlation, except in column 1 where the variables are measured in levels. ${ }^{26}$

\subsubsection{Alternative Specifications}

The regressions reported in columns (1)-(4) of Table 9 are rather parsimonious as to the set of conditioning variables included. Here we show that empirical correlation between labor taxes and unemployment in the EURO countries is not weakened by the inclusion of additional variables.

First we append country fixed effects to the OLS regression in differences. This would be the appropriate estimation method if there are country-specific deterministic time trends in unemployment. This is not the case, as shown in Table 9, column 5. The statistical significance of $E \tau^{L}$ stays unchanged, while the value of the adjusted R-squared falls dramatically from 0.16 to 0.02 , a clear symptom of over-parameterization.

Next, we add the one-period lagged unemployment rate (in levels) to the specification in first differences. This is a check on possible sluggish dynamic behavior of the unemployment rate, not picked up by the serial correlation tests reported at the bottom of the Table. Lagged unemployment is borderline significant; but its inclusion does not affect either the size or the significance of the $\tau^{L}$ coefficient in EURO (see

\section{Table 9, column 6).}

Third, we drop the recursivity assumption and include the growth rate of GDP per capita among the regressors of the unemployment equation, both in level and difference regressions. This could be appropriate if taking the five-year average is not sufficient to remove the cyclical component of unemployment, or more generally if there is a causal

\footnotetext{
${ }^{25}$ The standardized betas are the estimated coefficients in a regression where the original variables have been divided by their sample standard deviation so as to 'purge' the estimated coefficients of their dependence on measurement units.

${ }^{26}$ Given the relatively short time dimension of our sample, the test statistics are not very reliable and an acceptable p-value for the test may be well below the usual threshold of 0.05, as pointed out by MacKinnon (1992). Moreover, even correcting for the small sample bias as discussed by Kiviet (1986), the LM test can only be computed over a sample substantially smaller than the one over which the estimation is conducted, since we lose 14 observations.
} 
effect of growth on unemployment, as predicted by Aghion and Howitt (1994). Growth is treated as an endogenous variable, and the growth equation is specified as in Table 12, columns 1 and 2 (see also the discussion in subsection 3.5). The estimates are by 2SLS and are shown in Table 9, cols. 7 and 8. The estimated coefficient for growth is positive but insignificant when estimates are in levels. It takes a negative sign when estimates are in differences. In both cases, the statistical significance of the labor tax coefficient for EURO countries is unaltered and its size slightly increased after inclusion of the growth variable. Very similar results obtain if the growth rate of productivity per worker is substituted for the growth of GDP per capita.

Fourth, we included among the regressors variables capturing adverse macroeconomic shocks. If there is hystheresis in unemployment, it is possible that temporary adverse shocks leave unemployment permanently higher. The variables included were: the change in inflation (see Ball (1996)), the price of oil, and a set of time dummies for unobservable economic shocks. Some of these variables are occasionally statistically significant, depending on the specification and the estimation method, but the correlation between labor taxes and unemployment in the EURO countries survives and remains quantitatively large.

Finally, the results do not change if we include among the regressors a measure of trade-union density, such as the percentage of labor force belonging to a trade union. The variable was entered both linearly and as a quadratic term, to allow for possible nonlinearities, but was never statistically significant. We also experimented with other measures of trade union membership and concentration, but they were similarly statistically insignificant and their inclusion never affected the other estimated coefficients.

\subsubsection{Measurement error}

The labor tax rates and our measure of unemployment subsidies are certainly measured with error. To check the robustness of our results, we compute the consistent set of estimates suggested by Klepper and Leamer (1984) when all variables are measured with error. Thus, we regress equation (1) in Table 9 in the directions of all regressors, allowing the coefficients of $\tau^{L}$ on unemployment to vary across the three groups of 
countries $^{27}$. The consistent bounds for the coefficient of $E \tau^{L}$ in the unemployment regression are large but remain bounded away from zero. That is, despite likely measurement error in all the variables, the coefficient of $E \tau^{L}$ in the unemployment regression is consistently estimated to be positive. This is not the case instead for the other country groups. As noted above, the IV estimates also provide a check of robustness against measurement error.

Unemployment is also likely to be measured with error: different countries have different methods of recording the unemployed. Therefore we replace the unemployment rate with one minus the male employment rate (i.e., the ratio between male civilian employment and male population in working age). The results are even stronger. Table 10, column 1, reports IV estimates in first differences. The significance of the estimated coefficient of $\tau^{L}$ for EURO countries is enhanced. The regression diagnostics improve substantially and the test that the coefficients for EURO and ANGLO are equal is rejected at the $5 \%$ level of confidence, though not at the $1 \%$.

\subsubsection{Outliers and country groups}

The results are also robust to the presence of outlier observations and to changes in the definition of the country groups.

Given the exceptional value of Spanish unemployment since the mid-seventies, what happens if Spain is dropped from the sample? The answer is: not much. The estimated coefficient of labor taxes on unemployment drops somewhat in size in some specifications, but it remains clearly significant both in levels and first differences. Columns 2 and 3 in Table 10 present results for differenced data when Spain is left out and respectively unemployment and one minus the male employment rate are used as dependent variables. The estimated coefficient of $E \tau^{L}$ retains the same size and statistical significance as in the full sample, while the coefficients of the other variables are insignificant.

A second question concerns the definition of country groups. There is a margin of ambiguity in our classification, and a few countries are borderline cases between groups. Thus, we experiment with alternative classifications: we assign Belgium and Netherlands

\footnotetext{
${ }^{27}$ Thus, when we regress $\tau^{L}$ on the other variables, we let the coefficients of these other variables to vary across groups of countries, and so on.
} 
to the SCAND group, we put the UK in either the EURO or the ANGLO group for the whole period (i.e., with no break in the middle). Table 10 (cols. 4, 5 and 6) reports the estimates. The previous findings are not affected at all, except that the point estimates of $\tau^{L}$ for ANGLO and SCAND go up (but remain not significant). Moreover, a Wald test cannot reject the joint hypothesis that the UK in the Labour years belongs to ANGLO and that the UK in the Thatcher years belongs to EURO. ${ }^{28}$

\subsubsection{Nine-year averaging}

Lengthening the period over which the average is computed washes out business-cycle fluctuations, which may still be left in 5-year averaged data. The results of these experiments are shown in Table 10, columns 7 and $\mathbf{8 .}^{29}$ Naturally, the sample is now smaller. The results are very similar to those reported in Table 9, columns 1 and 2 . In particular, again $\tau^{L}$ is statistically significant from zero only in EURO, even though it drops in value somewhat. The restriction that the coefficients of $E \tau^{L}$ and $A \tau^{L}$ are equal is rejected, exactly like with 5-year averaged data. Finally, the coefficient of the replacement rate remains significant (albeit at the 10\% threshold of significance) even when estimating in differences.

\subsubsection{Summary of the unemployment equations}

In the countries of continental Europe, unemployment is strongly positively correlated with labor tax rates. This positive correlation sometimes also shows up, but it is much weaker, in the ANGLO group of countries, and it is never there in the Scandinavian countries. This correlation is mainly due to the time series variation in the data. It had not been found in previous studies for two reasons: first, such earlier studies had imposed the untested and false restriction that labor taxes affect unemployment equally in different countries. Second, most previous studies used shorter time series and often concentrated on the cross-country variation of unemployment.

Scandinavian countries stand out as an unresolved puzzle. We were unable to detect an effect of labor tax rates on unemployment in these countries. One reason could

\footnotetext{
${ }^{28}$ The result that the coefficient of $\tau^{L}$ is statistically different for EURO and SCAND countries would be indeed affected if, for example, Spain were assigned to the SCAND group. Yet a Wald test rejects the restriction that the unconstrained labor tax coefficient for Spain be the same as the coefficient of SCAND countries, while the restriction that Spain belongs to EURO is not rejected.
} 
indeed be the centralized structure of wage negotiations in these countries. But we are reluctant to draw this conclusion, also because indexes of coordination and centralization of union behavior are admittedly not very reliable. A second possible explanation is measurement error in unemployment in these countries. Most people fired in the Swedish private sector were recorded as still employed during the retraining programs lasting several months. Moreover, until recently the public sector absorbed workers that otherwise would have become unemployed, probably to a greater extent than in other industrial countries - see for instance Rosen (1996).

\section{$\underline{3.4 \text { Real wages }}$}

Now we investigate an additional implication of our model, that higher labor taxes feed into higher gross wages mostly in EURO countries. Testing this implication is important, because it can help us discriminate between our hypothesis and other candidate explanations of European unemployment. In the previous subsection we discussed one such explanation: some unobserved macroeconomic shock caused high unemployment in countries with labor market rigidities, and the correlation between labor tax rates and unemployment detected in Europe is spurious and just due to a common trend. In this case, however, there should not be any correlation between gross real wages and labor taxes, and more generally this correlation should be the same in Europe and elsewhere. This is not what we find in the data. Labor tax rates are correlated with gross real wages, but only in the EURO countries.

We use two alternative measures of real wages and of labor tax rates. The first one, denoted $\gamma_{w}$ in Table 11 and available for almost the full data set, is the growth of gross real wage earnings in manufacturing (see the data appendix for the sources). The specification is as described by (16) in subsection 2.5. The variables $\Delta \tau^{L}$ and $\Delta \sigma$ are measured as changes in the average tax and replacement rates across the five-year periods (except for the first observation, where the variation is computed between the end and the beginning of the period for lack of data). A positive estimated coefficient on the labor tax rates is evidence that the burden of taxation is shifted onto firms, a zero coefficient instead implies a reduction of net wages.

The second measure of real wages, denoted as $\gamma_{W N}$ in Table 11, is the growth of

\footnotetext{
${ }^{29}$ First differences are computed as indicated in footnote 22, but for the averaging period.
} 
net real wages of the average manufacturing worker (see the data appendix). Hence, here a zero estimated coefficient on the labor tax rate provides evidence that labor taxes increase the cost of labor, while the estimated coefficient should be negative if the burden of taxation is borne by the worker. This variable is available only from 1979 onwards. Thus, our panel consists of 14 countries and only 2 observations per country. In the net wage regressions, the measure of $\tau^{L}$ is different from that used in the rest of the paper : it is obtained from the same source that provides the net wage data and with a different method of computation (see the data appendix). The correlation coefficient between our two measures of $\tau^{L}$ is 0.60 in levels, 0.37 in first differences. These are low numbers, that underscore how important is the measurement error problem in $\tau^{L}$.

For both measures of wages, we first report the more parsimonious specification implied by the theoretical model (columns (1) and (3) of Table 11). In columns (2) and (4) we then add unemployment as a regressor, to allow for the moderating effect that unemployment could have on wage claims. We also replaced the growth rate of per capita income (implied by the model) with the growth rate of labor productivity, and the results (not reported) were roughly equivalent. The model is estimated by 2 SLS. ${ }^{30}$ The results are similar if the model is estimated by OLS, 3SLS or, in the case of gross wages, also by random effects.

Consider gross real wages first, in columns (1) and (2). As expected, higher labor tax rates lead to higher real wages in Europe but not elsewhere. Note however that, contrary to what happened in the unemployment regressions, now the Scandinavian countries have a higher estimated coefficient than the ANGLO countries, though it remains statistically insignificant. The growth and unemployment estimated coefficients are significant and with the expected sign. The only variable which, contrary to the model predictions, does not have a statistically significant estimated coefficient is the

\footnotetext{
${ }^{30}$ The specification of the growth equation is as reported in Table 12, column 2, with unemployment entering the growth equation in first differences, also treated as endogenous and specified as in column 2 of Table 9. When unemployment is added to the wage regression, the 2SLS model also consists of an unemployment equation in levels, specified as in column 1 of Table 9, and of the growth equation specified as in column 2 of Table 12. In other words, all RHS variables are in first differences except for unemployment that enters the growth equation in levels but its coefficient is constrained to be equal to the negative of that on lagged unemployment. The estimated coefficients of the wage regression are virtually identical if the growth and unemployment equations are always specified in levels, except that the LM test reveals a bigger serial correlation of the reduced form residual. Finally, in the case of $\gamma_{W N}$, the labor tax rates entering the unemployment equation are the same as those used in the $\gamma_{W N}$ regression.
} 
change in the replacement rate, $\Delta \sigma$. As usual, Spain is a bit of an outlier, as it had very high real wage growth. Dropping it from the sample reduces somewhat the size of the estimated coefficients on $\Delta \tau^{L}$ for the EURO countries, which however remains significant and higher than that of the other groups of countries. The results are also unaffected by the inclusion of time dummies in the real wage regression, while the inclusion of country dummies reduces the estimated coefficient of $\Delta \tau^{L}$ in the European countries which remains higher than in the other groups, but with a t-statistic of about 1.5. This suggests that the estimated tax rate coefficient is also picking up some cross country correlation in real wages. Finally, in one specification there is some evidence of serial correlation in the reduced form residuals, which however is due to the residuals in the unemployment equation and disappears when the wage equation is estimated by OLS.

Here too, we checked the robustness of our results against likely measurement error in all variables and in particular in $\tau^{L}$. Following Klepper and Leamer (1984), we estimated the wage regression by least squares in all directions, exploiting the recursivity assumption of the model. ${ }^{31}$ The consistent bounds for the coefficient of $E \tau^{L}$ in the wage equation are once again large but remain strictly positive and bounded away from zero. Thus, here too, measurement error does not seem to be responsible for our results.

Next, consider net real wages. Higher labor tax rates reduce the net real wage in the ANGLO countries, but not in EURO, as predicted. Moreover, labor tax rates do not affect net wages in the SCAND countries either, adding further support to the idea that the wage behavior in Scandinavia is more like in the rest of Europe than like in the ANGLO group. Finally, net real wages rise faster the higher is the growth rate of per capita GDP, as expected. Replacing GDP per capita with a measure of labor productivity leads to very similar results. Unemployment has the expected sign when included, but it is not statistically significant. Finally, the replacement rate has a positive but insignificant estimated coefficient. The results are robust to measurement error in all variables: the consistent bounds for $A \tau^{L}$ computed as in Klepper and Leamer (1984) are strictly negative. They are not very robust to other changes, however. They do not hold if the model is estimated by random effects, or if the sample is redefined to also cover a third subperiod, 1991-1994. Since not all variables are observed in this last subperiod,

\footnotetext{
${ }^{31}$ Even though we did not perform a Hausman specification test on the recursivity assumption, the OLS estimates are very close to the 2SLS estimates reported in Table $\mathbf{1 2 .}$
} 
however, here we change both the specification and the sample. Hence, we cannot tell what is responsible for the different results, whether a possibly mis-specified model or the different sample.

Overall, the data on real wages confirm the predictions of the model. Higher tax rates lead to higher gross wages in EURO but not elsewhere. While the data on net wages provide some, though more fragile, evidence that in a shorter and more recent sample the tax burden is borne by the workers in the ANGLO countries but it is shifted onto firms elsewhere.

A difference between the wage and the unemployment data concerns the behavior of the SCAND countries, for which there is some evidence of a partial shifting of labor taxes onto higher wages, but there is no evidence that higher taxes increase unemployment.

\section{$\underline{3.5 \text { Growth and investment }}$}

We now turn to the final block of our recursive model: the link between unemployment and growth. To check that our regressions of growth on unemployment are not just capturing a movement along the production function, we also change the dependent variable: in some regressions we replace the growth rate with the investment share of GDP, or with productivity growth.

\subsubsection{Estimation}

We start by estimating the growth and investment equations in levels. Besides unemployment and the capital tax rate, we also control for the log of initial GDP per capita, $Y$, and the initial secondary enrollment ratio, SCHOOL, as is now common in the growth literature. The estimation method is $2 \mathrm{SLS}$, and the instruments are the contemporaneous values of all exogenous variables in the entire model, namely $E \tau^{L}, \mathrm{~A} \tau^{L}$ $S \tau^{L}, \tau^{K}, \sigma, Y, S C H O O L$, as well as the full set of country dummies. The results are reported in Table 12, columns 1 and 4.

To allow for a country specific component in the error term, we also estimate the model in first differences. ${ }^{32}$ Thus, in the growth equation, we regress growth on the first

\footnotetext{
${ }^{32}$ Estimation by fixed effects in levels would yield biased estimates, because intial income is inclueded among the regressors (see for instance Hsiao (1986)). See Islam (1994) and Caselli, Esquivel and Leffort
} 
difference of all RHS variables (initial per capita income is then replaced by lagged growth). In the investment equation we do the same, except that investment is also measured in first differences. The estimation method is again 2SLS. To avoid the correlation between the RHS variables and the MA(1) component of the error term, we use as instruments the exogenous variables lagged once in first differences and lagged twice in levels, plus unemployment lagged once in first differences and twice in levels, as well as time dummies. The results are reported in Table 12, columns 2 and 5.

The estimated coefficient of unemployment is always negative and significant, as expected. It ranges between -0.09 in levels (column 1) and -0.15 in differences (column 2 ) in the growth regressions. And it ranges between -0.74 in differences (column 5) and -0.91 in levels (column 4) in the investment regressions. The results for growth are sensitive to the instrument choice, however. If time dummies are dropped from the instrument list, the coefficient of unemployment on growth is no longer statistically significant.

The capital tax rate is statistically significant in the investment regression in levels, but not in differences, and never in the growth regressions. The greater impact of the capital tax rate on investment than on growth is a feature of other empirical studies on industrial countries as well - see Mendoza, Milesi-Ferretti and Asea (1996).

The estimated coefficient of $Y$ (the log of initial GDP per capita) always has a negative sign, as expected, and it is statistically significant in the growth regressions. The value of -3.5 of the estimated coefficient of $\mathrm{Y}$ in column 1 is approximately half-way between the 'iron law of convergence' coefficient of about 2 found for many crosssections of regions and countries by Barro and Sala-i-Martin (1995, ch.12), and the much higher values found in panel studies. ${ }^{33}$ The estimated coefficient becomes smaller $(-0.7$, that is one minus the coefficient reported in column 2), but it stays significant at the $10 \%$ level, even when estimating in first differences. The estimated coefficient of SCHOOL has the expected positive sign but it is statistically significant only in the investment equation and its estimate varies somewhat across specifications and estimation methods.

To check whether these results are due to the time series or cross country

(1996) for a discussion of the estimation problems of growth regressions in panel data. See also Barro's (1996) defense of cross-sectional studies.

${ }^{33}$ The main point made in panel studies is that conventional cross-sectional studies produce biased estimates of the coefficients due to the omission of country fixed effects. See e.g. Islam (1994) and Caselli, 
variation in the data, we added time and country dummy variables to the regressions in levels. The results on investment are unaffected. The coefficients of unemployment and capital taxation in the growth regression, on the other hand, lose significance if country dummies are added to that equation, while they are only marginally affected by the inclusion of time dummies. $^{34}$

The last two lines of Table 12 report the $p$-values for the Jarque-Bera test (JB) for the normality of residuals and the degrees-of-freedom-corrected Lagrange Multiplier test (DFC-LM) for serial correlation. Both JB and DFC-LM tests detect departures from normality and serial correlation of order one in all level equations, particularly in the investment equation. Yet, the p-values for the LM test (though not for the JB test) improve considerably when estimating in first differences, which suggests that we are not over-differencing already detrended variables.

\subsubsection{Sensitivity Analysis}

These results are robust to a number of possible changes in the variable definitions or in the sample.

First, we change our measure of unemployment. In column 3, Table 12, unemployment is measured as one minus the male employment rate. The estimated unemployment coefficient on growth retains about the same size, but the estimated standard error is now smaller.

Second, we replace the growth rate of GDP per capita by the growth rate of productivity per worker The statistical significance of unemployment (measured in both ways) improves substantially (Table 12, columns 6 and 7).

Third, we average the data over 9-year intervals rather than over five years. The results remain very similar (Table 13, columns 1 and 2). Unemployment is more significant when estimating in levels than in first differences, and its significance in the difference regression crucially hinges on the inclusion of time dummies in the instrument list.

Fourth, we drop Spain from the sample. Some results worsen, others survive.

Table 13, column 3 reports the results of the growth regression in first differences. The

Esquivel and Lefort (1996).

${ }^{34}$ As already noted, however, fixed effects estimators could be biased because initial GDP per capita acts as a lagged endogenous variable. 
unemployment coefficient is no longer statistically significant: its pointwise estimate drops from -0.15 to -0.09 and the standard error of the estimate goes up to 0.10 . However, the results improve substantially when investment is the dependent variable or if unemployment is measured as one minus the male employment rate (Table 13, column 4).

As a final check, we added hours worked in the growth and investment regressions as an additional right-hand side variable. It was generally statistically insignificant and all other estimated coefficients were unaffected.

\subsubsection{Capital-labor ratios}

Finally, we turn to an analysis of the growth in the capital-labor ratio, which we expect to be positively related to the growth of real wages. The last column of Table 13 reports the estimates of the specification corresponding to equation (19) in subsection 2.5. The estimation method is 2SLS, where the specification for real wage growth is as in column (1) of Table 11, while growth and unemployment are respectively specified as in Table 12, column 1 and Table 9, column 1. The estimated coefficient on real wage growth is positive and highly significant, as expected. The estimated coefficient on growth is also positive, contrary to the model predictions, though it is only marginally significant. The results are very similar if GDP growth is replaced by the investment share of output. The results concerning the effect of real wages on the capital labor ratio are extremely robust, to the estimation method, to the inclusion of time or country dummy variables, to whether or not the estimates are weighted by initial per capita GDP to allow for possible heteroscedasticity. Finally, there is some evidence of serial correlation. If lagged per capita income is added to the regression, however, serial correlation disappears. The estimated coefficient on lagged per capita income is negative and statistically significant, while the growth coefficient becomes insignificantly different from zero. The real wage coefficient is unaffected.

Summarizing then, the empirical evidence strongly confirms the plausible prediction of the model, that higher real wages induce firms to substitute labor for capital.

\subsubsection{Summary and Quantitative Implications.}


In our sample, growth and investment are negatively correlated with unemployment, as predicted by a large class of growth models. This correlation is admittedly less robust than that between labor taxes and unemployment in EURO countries. And our empirical tests cannot shed light on whether this correlation is temporary or permanent. We can nevertheless ask, based on our estimates, how costly was the rise of labor taxes in Europe in the last twenty years, in terms of higher unemployment and slower growth.

Multiplying the estimated coefficient of $\tau^{L}$ by the unemployment coefficient in the growth equation, we can measure the induced effect of labor taxes on growth, and how it differs according to labor market institutions. For the EURO countries, the coefficient of $\tau^{L}$ in the unemployment equation is consistently significant and stable across a variety of specifications and estimation methods. Its estimated central value ranges between 0.31 and 0.65 , much larger than for the ANGLO and SCAND countries. Thus, for the EURO group, the compounded effect of $\tau^{L}$ on growth (through unemployment) lies between 0.040 and -0.075 , depending on the specifications and estimation methods. For the ANGLO and SCAND groups, on the other hand, the estimates are smaller and less stable. Though imprecisely estimated, the coefficient of $\tau^{K}$ in the growth equation is equal to -0.006 in Table 12, column 1. That is, for the EURO countries the estimated impact of $\tau^{K}$ on both growth and investment is always smaller than that indirectly induced by $\tau^{L}$ through unemployment.

These large numbers suggest that the surge in European unemployment and the European growth slowdown can be largely accounted for by the rise in labor taxes over time. Consider for instance Germany and France in 1965-1975 and 1976-1991, where labor tax rates rose by about 8 and 10 percentage points respectively between these two periods. According to our estimates, this could account for a reduction of growth of GDP per capita of about $0.4 \%$ per year, and an overall increase in unemployment of $3-5 \%$. Taking the EURO group as a whole, the rise in labor tax rates of $9.4 \%$ can be associated to an increase of $4 \%$ in the unemployment rate and a slowdown of per-capita GDP growth by about $0.4 \%$ a year. These are very large numbers. But so is a $10 \%$ point increase in labor tax rates. These figures compare with much smaller growth effects of the capital tax rate, of $-0.03 \%$ and $-0.10 \%$ in Germany and France respectively, which result from both smaller increases of the tax rate and lower values of the estimated coefficient. The sizable effect of labor taxes on growth is consistent with the findings of 
Mendoza, Milesi-Ferretti and Asea (1996), whose simulations broadly confirm Harberger's (1964) conjecture on the irrelevance of the tax structure for growth. A reduction of $10 \%$ in tax rates on capital income and consumption is shown to have negligible growth effects (of an order of magnitude of 0.1-0.2\%). Yet, taxes on human capital (what we call 'labor taxes') are instead found to be growth-enhancing. ${ }^{35}$

These results are particularly striking if compared with the reduced form regressions reported in Table 13, columns 6 and 7. In line with most of the studies in the applied growth literature, no effects of either capital or labor taxes show up in the reduced form growth regressions. How can we reconcile these reduced form results with the negative correlation of unemployment and growth, and the strong effect of labor tax rates on unemployment in Continental Europe ? One possible explanation is that the reduced form coefficient of $E \tau^{L}$ on growth is rather small (its order of magnitude is -0.05 or less even according to our indirect estimates). Thus, in the presence of measurement error, the reduced form estimates cannot reject that it is zero. To detect an effect of $E \tau^{L}$ on growth, we need to impose sharper restrictions on the precise mechanism through which it takes place. Our theory says that labor tax rates affect growth insofar as they affect unemployment, and they affect unemployment insofar as labor markets are dominated by strong and decentralized trade unions. These over-identifying restrictions can be tested using the LM specification test proposed by Hausman (1983, p.433). They cannot be rejected: the $p$-value of the test contrasting the reduced form estimates (Table 13, column 6) against the structural estimates is 0.78 (see the last line in Table 12, column 2). Hence, despite the statistical insignificance of the reduced form estimates, we do not reject the over-identifying assumptions of our structural model.

\section{Conclusions}

The surge in European unemployment undoubtedly has more than one cause. But, according to our empirical results, one is easy to identify: higher labor taxes have been shifted onto higher real wages. This has led firms to substitute labor with capital and it

\footnotetext{
${ }^{35}$ Mendoza, Milesi-Ferretti and Asea find that the effects of taxes on human capital may be even larger than ours (a $10 \%$ decrease of human capital taxation may result in a $1.5 \%$ rise of the growth rate). This is because they also allow for human capital to be reallocated across sectors, while our basic model does not explicitly take into account human capital accumulation.
} 
has slowed down economic growth. Thus, higher unemployment and slower growth in Europe are related, but in the sense that they stem from the same cause.

The policy implications of this view, if correct, would be extremely relevant. They concern the cost of the generous European welfare states, the optimal structure of taxation across alternative tax bases such as capital, labor or consumption, and the nature of the efficient remedies for the high unemployment.

Naturally, there are many chains to the argument put forward in this paper, and they ought to be investigated more in detail and with better data. Here are some questions worth exploring more in detail in future research. First, why has unemployment been so low in the Scandinavian countries, if indeed high taxes have been causing high unemployment in continental Europe? One possible answer suggested in the paper has to do with the high level of centralization and coordination of trade unions in Scandinavia, which has moderated their wage claims. But the real wage data explored in this model are not entirely consistent with this view. An alternative explanation is the expansion of public sector employment and the role that this might have had in preventing private sector unemployment in Scandinavia. The validity of this alternative explanation could be explored with disaggregated data on employment.

A second natural question concerns the role of international capital flows in the presence of different labor costs or tax treatments across countries. The theoretical model studied a closed economy, and the empirical analysis did not focus on the response of foreign direct investment to differences in the cost of labor. Adding these complications to our analysis is likely to reinforce the qualitative predictions of our model concerning the effect of labor taxes, and would increase the sensitivity of investment to capital taxes. Moreover, such a richer model could yield new testable implications. Hence, investigating both theoretically and empirically these questions in an open economy setting seems a natural and interesting extension of this work.

Finally, throughout the paper policy variables have been treated as exogenous. This is clearly not satisfactory. The same groups that are organized to bargain over wages are also able to influence economic policy, by lobbying or through other forms of political participation. Making economic policy endogenous and chosen by politically responsive governments in a dynamic framework, and possibly investigating the empirical implications of such a richer model, would be a difficult but exciting line of 
research. Caballero and Hammour (1996) have made some progress in this direction in a recent interesting paper. 


\section{References}

Aghion, P. and P.Howitt (1994), Growth and unemployment, Review of Economic Studies, 61, 477-495

Alesina, A. and R.Perotti, (1994), The Welfare State and competitiveness, NBER Working Paper

Alesina, A. and N.Roubini, with G.Cohen (1998), Political cycles and the macroeconomy, Boston, MIT Press, forthcoming

Alogoskoufis, G. et al. (1995), European unemployment: is there a solution?, London, CEPR

Arellano, M. and S.Bond, (1991), Some tests of specifications for panel data: Monte Carlo evidence and an application to employment equations, Review of Economic Studies, 58, 277-297

Ball, L. (1996), Disinflation and the NAIRU, NBER Working Paper \#5520, July

Barro, R.J. (1996), Determinants of economic growth: a cross-country empirical study, NBER Working Paper \#5698, August

Barro, R.J. and X. Sala-i-Martin (1995), Economic growth, McGrawHill

Basu, S. and J.G.Fernald (1995), Are apparent productive spillovers a figment of specification error?, Journal of Monetary Economics , 36, 165-188

Bean, C. (1994), European unemployment: a survey, Journal of Economic Literature, vol.32, 573-619

Bertola, G. (1993), Factor shares and savings in endogenous growth models, American Economic Review, 83, 1184-1198

Blanchard, O. (1996), Macroeconomics, MIT Press, ch.25

Blanchard, O. (1997), The Medium Term, mimeo, MIT

Blanchard, O. and L.F.Katz (1996), What we know and do not know about the natural rate of unemployment, NBER Working Paper \#5822, November

Bruno M., and J.D.Sachs (1985), Economics of worldwide stagflation, Cambridge, Mass., Harvard University Press

Burnside, C. (1996), Production function regressions, returns to scale, and externalities, Journal of Monetary Economics, 37, 177-201 
Caballero, R. and M.L.Hammour (1996), The Macroeconomics of Specificity; NBER Working Paper \#5757, September

Caballero, R. and R.Lyons (1992), External effects in U.S. manufacturing, Journal of Monetary Economics, 29, 209-226

Calmfors L. and J. Driffill (1988) "Bargaining Structure, Corporativism and Macroeconomic Performance", Economic Policy, vol. 6

Cameron D.R. (1984), Social democracy, corporatism, labor quiescence and the representation of economic interest in advanced capitalist society, in J.H.Goldthorpe (ed.), Order and conflict in contemporary capitalism, Oxford, Clarendon Press

Caselli, F., G.Esquivel and F.Lefort (1996), Reopening the convergence debate: a new look at cross-country growth empirics, Journal of Economic Growth

Furuya, K. (1995), Capital, savings and unemployment, mimeo, Berkeley University

Golden, M. (1996), Union centralization among advanced industrial societies: an empirical study, UCLA, mimeo

Gordon, R. (1995), Is there a trade-off between unemployment and productivity growth?, CEPR Discussion Paper \#.1159, April

Hsiao, C. (1986), The analysis of panel data, Cambridge, Cambridge University Press

Islam, N. (1994), Growth empirics: a panel data approach, Quarterly Journal of Economics, 110, 1127-1170

Jones, L., R.Manuelli (1990), A convex model of equilibrium growth, Journal of Political Economy, 98, 1008-1038

Jones, L., R.Manuelli and P.Rossi (1993), Optimal taxation in models of endogenous growth, Journal of Political Economy, 101, 485-517

Kiviet, J.F. (1986), On the rigour of some misspecification tests for modelling dynamic relationships, Review of Economic Studies, 53, 241-261

Klepper S. and E.E.Leamer (1984), Consistent sets of estimates for regressions with errors in all variables, Econometrica, 52, 163-183

Layard, R., S.Nickell and R.Jackman (1991), Unemployment: Macroeconomic performance and the labour market, Oxford, Oxford University Press

Lindbeck, A. (1993), Unemployment and macroeconomics, MIT Press

Lucas, R.J.E..Jr. (1988), On the mechanics of economic development, Journal of Monetary Economics, 2-40 
Lucas, R.J.E..Jr. (1990), Supply-side economics: an analytical survey, Oxford Economic Papers, 42, 293-316

Lucas, R.J.E..Jr. (1993), Making a miracle, Econometrica, 61, 251-272

MacKinnon, J.g. (1992), Model specification tests and artificial regressions, Journal of Economic Literature, 30, 102-146

Mendoza, E., G.Milesi-Ferretti and P.Asea (1996), On the ineffectiveness of tax policy in altering long-run growth: Harberger's superneutrality conjecture, CEPR Discussion Paper \#1378, April

Mendoza, E., A.Razin and L.Tesar (1994), Effective tax rates in macreconomics: crosscountry estimates of tax rates on factor incomes and consumption, Journal of Monetary Economics, 34, 297-323

Mortensen, D.T. and C.Pissarides (1997), Job reallocation, employment fluctuations and unemployment differences, in J.Taylor and M.Woodford, Handbook of Macroeconomics, vol.III, North Holland, forthcoming

Nickell, S. (1997), Unemployment and Labor Market Rigidities, The Journal of Economic Perspectives, August

OECD (1994), The OECD Jobs Study, Paris, OECD

OECD (1997), Employment Outlook, Paris, OECD

Padoa Schioppa, F. (1990), Union wage setting and taxation, Oxford Bulletin of Economics and Statistics, 52, 143-166

Persson, T. and G.Tabellini (1997), Political economics and macroeconomics, in J.E.Taylor and M.Woodford, Handbook of Macroeconomics, Amsterdam, North Holland

Phelps, E.S. (1968), Money-wage dynamics and labor market equilibrium, Journal of Political Economy, 76, 678-711

Phelps, E.S. (1994), Structural slumps: the modern equilibrium theory of unemployment, interest and assets, Cambridge, Mass., Harvard University Press

Rebelo, S. (1991), Long-run policy analysis and long-run growth, Journal of Political Economy, 99, 500-521

Romer, P.R. (1986), Increasing returns and long-run growth, Journal of Political Economy, 94, 1002-1037

Romer P.R. (1989), Capital accumulation and long-run growth, in R.J.Barro, Modern business-cycle theory, Oxford, Basil Blackwell 
Romer, P.R. (1990), Endogenous technical change, Journal of Political Economy, 98, S71-S102

Rosen, S. (1996), Public employment and the welfare state in Sweden, Journal of Economic Literature, 34, 729-740

Stokey N.L. and S.Rebelo (1995), Growth effects of flat-tax rates, Journal of Political Economy, 103, 519-550

Summers, L., J.Gruber and R.Vergara (1993), Taxation and the structure of labor markets: the case of corporatism, Quarterly Journal of Economics, 385-411

Tullio, G. (1987), Long-run implications of the increase in taxation and public debt for employment and economic growth in Europe, European Economic Review, 20, 741-774

Tyrvainen, T. (1994), Real wage resistance and unemployment: multivaraite analysis of cointegrating relations in 10 OECD countries, mimeo, Paris, OECD

Van der Ploeg, F. (1987), Trade unions, employment and investment: a non-cooperative approach, European Economic Review, 31, 1465-1492

Young, A. (1993), Lessons from the East Asian NICs: a contrarian view, European Economic Review, 38, 964-973 


\section{Data Appendix}

List of variables: definitions and sources.

$\boldsymbol{u}=$ standardized unemployment rate. Source: OECD National Accounts. In some regressions, $u$ is the complement to one of the employment rate (the number of the civilian employed divided by population in working age), expressed in percentage points. Source: OECD Labor Force Statistics.

$\boldsymbol{g}=$ Growth rate of per-capita GDP. Source: Summers-Heston data set (PWT 5.6).

$\boldsymbol{Y}=$ level of initial per capita GDP. Source : Summers-Heston data set (PWT 5.6).

$\tau^{L}=$ Effective tax rate on labor income: Computed as the ratio between total taxes on labor income ( $=$ an imputation of taxes on wages and salaries from the individual income tax + social security contributions + payroll taxes) and the labor tax base (=wages and salaries + employers' contributions to social security). Missing a full series, the tax rates for few countries are computed as the average between two data points (e.g. 1965 and 1970 for the 1965-70 quinquennium for Netherlands, Italy, Spain and Norway). Primary source: OECD National Accounts, OECD Revenue Statistics. Again, due to data coverage problems, the data on labor tax rates employed in the net wage equations are drawn from another OECD publication, The tax/benefit position of production workers.

$\tau^{K}=$ Effective tax rate on capital income: Computed as the ratio between total taxes on capital income ( $=$ an imputation of taxes on the operating surplus of unincorporated enterprises and profits and entrepreneurial incomes + corporate taxes + recurrent taxes on immovable property + taxes on financial and capital transactions) and its tax base (= total operating surplus of the economy). Missing a full series, the tax rates for few countries are computed as the average between two data points (e.g. 1965 and 1970 for the 196570 quinquennium for Netherlands, Italy, Spain and Norway). Primary source: OECD National Accounts, OECD Revenue Statistics.

$\boldsymbol{i}=$ Investment: Domestic investment as a share of GDP at constant prices. Source: Summers-Heston data set (PWT 5.6).

$\sigma=$ Replacement rate in unemployment benefits: Computed as a summary measure of replacement rates, i.e. ratio between benefit entitlements and previous earnings, both before tax, for a variety of circumstances (period of unemployment spell, family situation, previous level of earnings). Primary source: OECD Jobs Study, Database on Unemployment Benefit Entitlements and Replacement Rates.

$\gamma_{k / l}=$ growth in the stock of physical capital per employee: The variable in levels has been computed as the ratio between the capital stock per worker (source: PWT 5.6) and the employment rate $(=1$-standardized unemployment rate; source: OECD National Accounts). 
$\gamma_{w}=$ Growth of real wages: growth in hourly pre-tax wage earnings in manufacturing, deflated with the CPI . Source: OECD National Accounts and Main Economic Indicators.

$\gamma_{w n}=$ Growth of net real wages: growth in take-home pay and cash transfers after taxes and from annual gross earnings of a single person. Source: OECD, Tax and benefit position of production workers, various issues.

$S C H O O L=$ Gross secondary enrollment ratio in the initial year of the quinquennium: number of persons enrolled in the secondary school as a share of population aged 14-18. 
Table 1

\section{UNEMPLOYMENT \& GROWTH IN INDUSTRIAL COUNTRIES}

\begin{tabular}{|c|c|c|c|c|c|c|c|}
\hline & \multicolumn{3}{|c|}{ Unemployment } & \multicolumn{4}{|c|}{ Per-capita GDP Growth } \\
\hline & $1965-75$ & \multicolumn{2}{|c|}{$1976-95$} & \multicolumn{2}{|c|}{$1965-75$} & \multicolumn{2}{|c|}{$1976-95$} \\
\hline - EUROPE & 2.6 & 8.5 & & 3.5 & & 1.7 & \\
\hline $\begin{array}{l}\text { - EC } \\
\text { - SCANDINAVIA } \\
\end{array}$ & $\begin{array}{l}2.8 \\
2.0 \\
\end{array}$ & & $\begin{array}{l}9.4 \\
4.8 \\
\end{array}$ & & $\begin{array}{l}3.4 \\
3.4 \\
\end{array}$ & & $\begin{array}{l}1.7 \\
1.5 \\
\end{array}$ \\
\hline - NON-EUROPE & 3.4 & 6.5 & & 3.5 & & 1.8 & \\
\hline $\begin{array}{l}\text { - US \& CANADA } \\
\text { - JAPAN } \\
\text { - AUSTRALIA }\end{array}$ & $\begin{array}{l}5.0 \\
1.3 \\
2.3\end{array}$ & & $\begin{array}{l}8.0 \\
2.4 \\
7.7\end{array}$ & & $\begin{array}{l}2.8 \\
6.0 \\
2.3\end{array}$ & & $\begin{array}{l}1.5 \\
3.0 \\
1.2\end{array}$ \\
\hline
\end{tabular}

Source: OECD National Accounts and Summers-Heston data set 


\section{Table 2}

Effective Tax Rates on Labor Income

\begin{tabular}{|c|c|c|c|c|c|}
\hline Country/Year & $\mathbf{1 9 6 5 - 7 0}$ & $\mathbf{1 9 7 1 - 7 5}$ & $\mathbf{1 9 7 6 - 8 0}$ & $\mathbf{1 9 8 1 - 8 5}$ & $\mathbf{1 9 8 6 - 9 1}$ \\
\hline Australia & 11.7 & 14.1 & 16.5 & 17.9 & 18.2 \\
Belgium & 30.5 & 36.4 & 41.7 & 45.3 & 47.7 \\
Canada & 17.1 & 22.0 & 22.6 & 25.0 & 29.2 \\
Finland & 20.7 & 28.1 & 30.9 & 31.1 & 33.9 \\
France & 33.9 & 33.0 & 37.9 & 42.4 & 45.7 \\
Germany & 30.5 & 35.1 & 38.3 & 38.9 & 41.7 \\
Italy & 26.1 & 28.7. & 32.0 & 37.0 & 41.4 \\
Japan & 16.0 & 18.1 & 20.6 & 24.4 & 27.5 \\
Netherlands & 36.1 & 42.7 & 47.1 & 50.1 & 51.8 \\
Norway & 31.0 & 38.9 & 38.7 & 38.4 & 39.8 \\
Spain & 15.4 & 20.2 & 26.4 & 32.8 & 36.4 \\
Sweden & 34.3 & 38.9 & 47.2 & 48.1 & 50.9 \\
UK & 22.6 & 24.7 & 26.7 & 27.1 & 25.7 \\
USA & 20.1 & 23.0 & 26.1 & 28.3 & 28.9 \\
\hline
\end{tabular}

Legenda: Effective tax rates are constructed following the methodology suggested by Mendoza, Razin and Tesar (1994). See also the Data Appendix.

Primary source : OECD National Accounts, various issues 


\section{Table 3}

Effective Tax Rates on Capital Income

\begin{tabular}{|c|c|c|c|c|c|}
\hline Country/Year & $1965-70$ & $1971-75$ & $1976-80$ & $1981-85$ & $1986-91$ \\
\hline Australia & 31.7 & 38.8 & 41.4 & 44.5 & 47.4 \\
Belgium & 19.7 & 28.0 & 37.3 & 39.5 & 36.3 \\
Canada & 41.0 & 43.4 & 39.6 & 37.9 & 43.1 \\
Finland & 24.0 & 28.1 & 35.8 & 35.2 & 44.1 \\
France & 16.2 & 18.0 & 23.9 & 28.4 & 26.1 \\
Germany & 21.2 & 24.8 & 29.4 & 31.0 & 27.8 \\
Italy & 12.8 & 13.1 & 17.0 & 25.3 & 28.6 \\
Japan & 20.5 & 28.8 & 32.6 & 39.7 & 49.3 \\
Netherlands & 23.9 & 28.9 & 33.5 & 29.7 & 30.9 \\
Norway & 29.0 & 27.3 & 37.3 & 42.6 & 38.7 \\
Spain & 8.2 & 9.7 & 12.7 & 13.9 & 14.1 \\
Sweden & 36.2 & 39.9 & 54.1 & 47.4 & 63.9 \\
UK & 46.7 & 56.6 & 55.7 & 66.5 & 58.3 \\
USA & 42.0 & 44.3 & 44.7 & 40.9 & 41.0 \\
\hline
\end{tabular}

Legenda: Effective tax rates are constructed following the methodology suggested by Mendoza, Razin and Tesar (1994). See also the Data Appendix.

Primary source : OECD National Accounts, various issues 
Table 4 - Pairwise Correlation Coefficients

\begin{tabular}{|c|c|c|c|c|c|c|c|c|}
\hline $\boldsymbol{u}, \tau^{L}$ & $\boldsymbol{u}, \boldsymbol{\sigma}$ & $\boldsymbol{g}, \tau^{\boldsymbol{L}}$ & $\boldsymbol{g}, \tau^{K}$ & $\boldsymbol{g}, \boldsymbol{u}$ & $\boldsymbol{i}, \boldsymbol{u}$ & $\boldsymbol{i}, \tau^{K}$ & $\gamma_{\boldsymbol{w}}, \Delta \tau^{L}$ & $\gamma_{\boldsymbol{w}}, \gamma_{\boldsymbol{k} / \boldsymbol{l}}$ \\
\hline .20 & .25 & -.27 & -.30 & -.37 & -.51 & -.44 & .16 & .68 \\
\hline
\end{tabular}

Over Time

\begin{tabular}{|c|c|c|c|c|c|c|c|c|c|}
\hline & $u, \tau^{L}$ & $u, \sigma$ & $g, \tau^{L}$ & $g, \tau^{K}$ & $g, u$ & $i, u$ & $i, \tau^{K}$ & $\gamma_{w}, \Delta \tau^{L}$ & $\gamma_{w}, \gamma_{k / l}$ \\
\hline US & .78 & $\begin{array}{l}.08 \\
\end{array}$ & -.55 & .17 & -.38 & -.68 & .31 & .73 & .67 \\
\hline UK & .79 & -.69 & -.04 & .15 & .51 & -.90 & -.91 & -.20 & .38 \\
\hline Belgium & .91 & .57 & -.63 & -.73 & -.82 & -.94 & -.80 & .50 & .81 \\
\hline France & .98 & .86 & -.60 & -.82 & -.73 & -.88 & -.94 & -.81 & .94 \\
\hline Germany & .87 & -.54 & -.32 & -.45 & -.44 & -.99 & -.91 & .48 & .74 \\
\hline Italy & 99 & -.83 & -.54 & -.52 & -.46 & -.90 & -.91 & -.98 & .94 \\
\hline Netherlands & .92 & .67 & -.81 & -.68 & -.83 & -.98 & -.69 & .77 & .94 \\
\hline Norway & .43 & .96 & -.13 & -.34 & -.93 & -.96 & -.76 & .98 & -.73 \\
\hline Sweden & .36 & .36 & -.92 & -.88 & -.14 & -.73 & -.58 & -.12 & .72 \\
\hline Canada & .80 & .77 & -.86 & .07 & -.73 & .46 & .29 & .44 & -.11 \\
\hline Japan & .94 & -.89 & -.53 & -.60 & -.60 & -.47 & -.13 & -.84 & .99 \\
\hline Finland & .76 & .85 & -.97 & -.98 & -.79 & -.94 & -.88 & .74 & .92 \\
\hline Spain & .96 & .93 & -.43 & -.11 & -.37 & -.67 & -.62 & -.19 & .90 \\
\hline Australia & .98 & .90 & -.79 & -.89 & -.67 & -.90 & -.99 & .47 & .90 \\
\hline
\end{tabular}

Across Countries

\begin{tabular}{|cccccccccc|}
\hline & $\boldsymbol{u}, \tau^{\boldsymbol{L}}$ & $\boldsymbol{u}, \boldsymbol{\sigma}$ & $\boldsymbol{g}, \tau^{\boldsymbol{L}}$ & $\boldsymbol{g}, \tau^{K}$ & $\boldsymbol{g}, \boldsymbol{u}$ & $\boldsymbol{i}, \boldsymbol{u}$ & $\boldsymbol{i}, \tau^{K}$ & $\boldsymbol{\gamma}_{\boldsymbol{w}}, \Delta \tau^{L}$ & $\boldsymbol{\gamma}_{\boldsymbol{w}}, \boldsymbol{\gamma}_{\boldsymbol{k} \boldsymbol{l}}$ \\
\hline $\mathbf{1 9 6 5 - 7 0}$ & -.27 &.- .37 & -.24 & -.64 & -.15 & -.39 & -.59 & -.27 & .66 \\
\hline $\mathbf{1 9 7 1 - 7 5}$ & -.29 & -.11 & 0 & -.33 & -.14 & -.60 & -.53 & .14 & .35 \\
\hline $\mathbf{1 9 7 6 - 8 0}$ & -.27 & .23 & .01 & -.22 & -.19 & -.47 & -.38 & .23 & .74 \\
\hline $\mathbf{1 9 8 1 - 8 5}$ & 0 & .30 & -.53 & .53 & -.70 & -.57 & -.22 & .02 & .37 \\
\hline $\mathbf{1 9 8 6 - 9 1}$ & .01 & .12 & .15 & -.44 & .47 & -.20 & -.07 & -.04 & -.07 \\
\hline
\end{tabular}

Legenda : see the data appendix for the definitions. 


\section{Table 5}

\section{Coverage, density and coordination of labor bargaining in Industrial Countries}

\begin{tabular}{|c|c|c|c|c|c|c|}
\hline \multirow[t]{2}{*}{ Country } & \multicolumn{2}{|c|}{ Coverage } & \multicolumn{2}{|c|}{ Density } & \multicolumn{2}{|c|}{ Coordination } \\
\hline & 1980 & 1990 & 1976-86 & 1986-91 & Union & Employer \\
\hline & & & JGLO & & & \\
\hline Canada & 37 & 38 & 26 & 32 & 1 & 1 \\
\hline Japan & 28 & 23 & 31 & 26 & 2 & 2 \\
\hline USA & 26 & 18 & 23 & 15 & 1 & 1 \\
\hline United Kingdom & 70 & 47 & 48 & 39 & 1 & 1 \\
\hline & & & JRO & & & \\
\hline Australia & 88 & 80 & 46 & 44 & 2 & 1 \\
\hline Belgium & 90 & 90 & 55 & 54 & 2 & 2 \\
\hline France & 85 & 92 & 19 & 12 & 2 & 2 \\
\hline Germany & 91 & 90 & 35 & 31 & 2 & 3 \\
\hline Italy & 85 & 83 & 45 & 34 & 2 & 2 \\
\hline Netherlands & 76 & 71 & 35 & 23 & 2 & 2 \\
\hline Spain & 68 & 68 & 25 & 11 & 2 & 1 \\
\hline & & & AND & & & \\
\hline Finland & 95 & 95 & 69 & 71 & 2 & 3 \\
\hline Norway & 75 & 75 & 52 & 54 & 3 & 3 \\
\hline Sweden & 83 & 83 & 76 & 83 & 3 & 3 \\
\hline
\end{tabular}

Source: OECD Jobs Study for coverage ratios; Nickell (1997) for cordination, Golden (1996) for union density rates.

Notes:

"Coverage" measures the extent to which contracts signed by organized unions extend to the rest of the labor force.

"Density" measures the rates of net union density, i.e. the number of union members net of pensioners divided by the labor force.

"Coordination" measures the extent of contracting coordination within different union and employer organizations in 1989-94. The index provides a qualitative ranking of countries: "1"means "Low", "2" is for "Medium", " 3 " is for "High". 


\section{Table 6}

\section{Unemployment and Growth}

\begin{tabular}{|c|c|c|c|c|c|c|c|c|}
\hline & \multicolumn{2}{|c|}{ Europe } & \multicolumn{2}{|c|}{ Anglo } & \multicolumn{2}{|c|}{ Scand } & \multicolumn{2}{|c|}{ All Countrie } \\
\hline & $D U$ & $\boldsymbol{G}$ & $D U$ & $\boldsymbol{G}$ & $D U$ & $\boldsymbol{G}$ & $D U$ & $\boldsymbol{G}$ \\
\hline 1965-70 & 0.4 & 4.1 & -0.9 & 4.6 & 0.3 & 3.6 & 0 & 4.2 \\
\hline 1971-75 & 0.8 & 2.4 & 1.3 & 2.3 & 0.1 & 3.2 & 0.8 & 2.6 \\
\hline 1976-80 & 2.8 & 2.5 & 1.5 & 2.6 & 1.0 & 2.6 & 2.0 & 2.6 \\
\hline 1981-85 & 4.6 & 0.6 & 2.5 & 2.1 & 0.6 & 2.3 & 3.0 & 1.5 \\
\hline 1986-91 & -0.4 & 2.9 & -1.4 & 1.8 & -0.9 & 1.0 & -0.7 & 2.1 \\
\hline All Years & 1.6 & 2.6 & 0.6 & 2.6 & 0.4 & 2.5 & & \\
\hline
\end{tabular}

$D U$ denotes the change in the unemployment rate, measured as the first difference of the five (or six) year averages.

$G$ is the average growth rate of per capita income during each five (or six) years period.

Each column displays the average of the above variables across countries, within the relevant country groups, for each time period. The raw "All years" refers to the simple average across both time and countries, within the relevant country groups.

The country groups are those described in Table 5. 


\section{Table 7}

Tax Rates and Replacement Rates

\begin{tabular}{|c|c|c|c|c|c|c|c|c|c|c|c|c|}
\hline & \multicolumn{3}{|c|}{ Europe } & \multicolumn{3}{|c|}{ Anglo } & \multicolumn{3}{|c|}{ Scand } & \multicolumn{3}{|c|}{ All Countries } \\
\hline & $\Delta \sigma$ & $\Delta \tau^{k}$ & $\Delta \tau^{\perp}$ & $\Delta \sigma$ & $\Delta \tau^{k}$ & $\Delta \tau^{\downarrow}$ & $\Delta \sigma$ & $\Delta \tau^{k}$ & $\Delta \tau^{\prime}$ & $\Delta \sigma$ & $\Delta \tau^{k}$ & $\Delta \tau^{\prime}$ \\
\hline 1965-70 & 3.6 & 1.7 & 1.7 & -0.7 & 2.5 & 2.2 & -0.1 & 2.8 & 3.2 & 1.6 & 2.1 & 2.2 \\
\hline 1971-75 & 2.7 & 4.4 & 3.7 & 2.0 & 5.0 & 3.1 & 4.6 & 2.0 & 6.6 & 2.9 & 4.1 & 4.1 \\
\hline 1976-80 & 1.0 & 4.2 & 4.2 & 2.8 & 0.8 & 2.2 & 12.5 & 10.6 & 3.7 & 4.0 & 4.6 & 3.5 \\
\hline 1981-85 & 0.8 & 2.5 & 3.9 & -1.1 & 3.1 & 2.0 & 4.6 & -0.7 & 0.3 & 0.9 & 2.0 & 2.4 \\
\hline 1986-91 & 3.2 & 0.3 & 3.0 & -0.2 & 1.9 & 1.3 & 8.6 & 7.1 & 2.4 & 3.1 & 2.3 & 2.3 \\
\hline All Years & 2.3 & 2.7 & 3.3 & 0.4 & 2.6 & 2.1 & 6.0 & 4.4 & 3.2 & & & \\
\hline
\end{tabular}

$\Delta \sigma$ denotes the change in the replacement rate, $\Delta \tau^{\kappa}$ is the change in the capital tax rate, $\Delta \tau^{L}$ is the change in the labor tax rate. All variables are measured as the first difference of the relevant five (or six) year averages.

Each column displays the average of the above variables across countries, within the relevant country groups, for each time period. The raw "All years" refers to the simple average across both time and countries, within the relevant country groups.

The country groups are those described in Table 5. 


\section{Table 8}

\section{Real Wages and Capital Labor Ratio}

(\% growth rate)

\begin{tabular}{ccccccccc} 
& \multicolumn{2}{c}{ Europe } & \multicolumn{2}{c}{ Anglo } & \multicolumn{2}{c}{ Scand } & \multicolumn{2}{c}{ All Countries } \\
& $\gamma_{w}$ & $\gamma_{k \prime l}$ & $\gamma_{w}$ & $\gamma_{k / l}$ & $\gamma_{w}$ & $\gamma_{k / l}$ & $\gamma_{w}$ & $\gamma_{k / l}$ \\
$\mathbf{1 9 6 5 - 7 0}$ & 5.0 & 7.4 & 3.4 & 7.0 & 4.5 & 4.0 & 4.4 & 6.6 \\
$\mathbf{1 9 7 1 - 7 5}$ & 5.4 & 7.3 & 3.6 & 6.5 & 4.2 & 3.4 & 4.7 & 6.2 \\
$\mathbf{1 9 7 6 - 8 0}$ & 2.6 & 3.8 & 0.8 & 2.8 & 0.5 & 2.4 & 1.6 & 3.2 \\
$\mathbf{1 9 8 1 - 8 5}$ & 0.7 & 2.7 & 1.0 & 3.1 & 0.7 & 2.2 & 0.8 & 2.8 \\
$\mathbf{1 9 8 6 - 9 1}$ & 1.4 & 2.1 & 0.6 & 3.6 & 1.8 & 3.3 & 1.2 & 2.9 \\
All Years & 3.0 & 4.8 & 1.7 & 4.5 & 1.9 & 3.0 & &
\end{tabular}

$\gamma_{w}$ and $\gamma_{k / l}$ denote the average growth rate of real wages and of the capital-labor ratio respectively, measured as five (or six) year averages of the yearly growth rates.

Each column displays the average of the above variables across countries, within the relevant country groups, for each time period.

The raw "All years" refers to the simple average across both time and countries, within the relevant country groups.

The country groups are those described in Table 5. 
Table 9

\begin{tabular}{|c|c|c|c|c|c|c|c|c|}
\hline \multicolumn{9}{|c|}{$\begin{array}{l}\text { UNEMPLOYMENT AND LABOR TAXES } \\
\text { (5-YEAR AVERAGES) } \\
\end{array}$} \\
\hline & [1] & [2] & [3] & {$[4]$} & [5] & [6] & [7] & [8] \\
\hline $\begin{array}{l}\text { Method of } \\
\text { estimation }\end{array}$ & OLS & OLS & GLS & IV & OLS & IV & 2SLS & 2SLS \\
\hline Dep.variable & $u$ & $\Delta \mathbf{u}$ & $\Delta \mathbf{u}$ & $\Delta \mathbf{u}$ & $\Delta \mathbf{u}$ & $\Delta \mathbf{u}$ & $\mathbf{u}$ & $\Delta \mathbf{u}$ \\
\hline \multirow[t]{2}{*}{$A \tau^{L}$} & $0.26^{\star \star \star *}$ & 0.04 & -0.021 & 0.48 & 0.21 & 0.35 & $0.38^{\text {knt }}$ & $0.626^{*}$ \\
\hline & $(0.09)$ & $(0.198)$ & $(0.15)$ & $(0.384)$ & $(0.42)$ & $(0.388)$ & $(0.130)$ & $(0.378)$ \\
\hline \multirow[t]{2}{*}{$E \tau^{L}$} & $0.55^{\star \star \star *}$ & $0.44^{\star * *}$ & $0.37^{\star \star \star}$ & $0.65^{\star \star x *}$ & $0.59^{\star \star \star}$ & $0.58^{\star *}$ & $0.61^{\text {tat }}$ & $0.723^{*+x}$ \\
\hline & $(0.05)$ & $(0.129)$ & $(0.10)$ & $(0.228)$ & $(0.21)$ & $(0.230)$ & $(0.069)$ & $(0.215)$ \\
\hline \multirow[t]{2}{*}{$S \tau^{L}$} & -0.13 & -0.04 & -0.02 & 0.025 & -0.09 & -0.23 & -0.10 & 0.221 \\
\hline & $(0.11)$ & $(0.143)$ & $(0.12)$ & $(0.351)$ & $(0.21)$ & $(0.376)$ & $(0.129)$ & $(0.337)$ \\
\hline \multirow[t]{2}{*}{$\sigma$} & $0.12^{\star \star \star}$ & 0.013 & 0.03 & -0.005 & -0.01 & -0.005 & $0.143^{\text {tht }}$ & -0.017 \\
\hline & $(0.04)$ & $(0.046)$ & $(0.04)$ & $(0.136)$ & $(0.06)$ & $(0.134)$ & $(0.051)$ & $(0.110)$ \\
\hline \multirow[t]{2}{*}{$u_{t-1}$} & - & - & - & - & - & -0.192 & - & - \\
\hline & & & & & & $(0.104)$ & & \\
\hline & & & & & & & & \\
\hline \multirow[t]{2}{*}{$g$} & - & - & - & - & - & - & 0.529 & $-0.712^{*}$ \\
\hline & & & & & & & $(0.329)$ & $(0.378)$ \\
\hline \#obs & 70 & 70 & 70 & 56 & 70 & 56 & 70 & 56 \\
\hline Adj. $R^{2}$ & 0.86 & 0.16 & & 0.16 & 0.02 & 0.19 & 0.82 & 0.20 \\
\hline SEE & 1.38 & 1.88 & 0.97 & 2. 08 & 2.04 & 2.06 & 1.60 & 2.07 \\
\hline \multicolumn{9}{|c|}{ P-VALUES FOR: } \\
\hline JB test & 0.002 & 0.27 & & 0.28 & 0.04 & 0.24 & 0.001 & 0.01 \\
\hline DFC-LM test & 0.03 & 0.07 & & 0.11 & 0.02 & 0.12 & 0.01 & 0.07 \\
\hline $\begin{array}{l}\text { Wald test: } \\
\text { Anglo=Euro }\end{array}$ & 0.01 & 0.03 & & 0.22 & & 0.03 & 0.06 & 0.71 \\
\hline
\end{tabular}

Notes:

Column [1] : All variables in levels, fixed effects estimation

Columns [2]: All variables in first differences, estimated without fixed effects.

Columns [3]: All variables in first differences, estimated by GLS allowing for MA(1) in the error term but no

correlation across countries.

Columns [4],[6]: All variables in first differences, except $u_{t-1}$ which is in levels. Instruments: Right-hand side variables in levels and first differences lagged twice and once respectively; time dummies.

Column [5] : Country fixed effects included as intercepts. All variables in first differences.

Column [7]: All variables in levels. Estimated by 2SLS, with fixed effects in the unemployment equation. The growth equation is specified as in Table 12, column (1).

Column [8]: All variables except growth in first differences. Estimated by 2SLS. The growth equation is specified as in Table 11, column (2). All exogenous and predetermined variables in the unemployment and in the growth equations are instrumented with a set of instruments consisting of: all exogenous and predetermined variables lagged twice in levels and once in first differences, plus time dummies.

Fixed-effects intercepts and constants not reported. Standard errors in parentheses.

$* \quad=10 \%$ level of significance

$* * \quad=5 \%$ level of significance

$* * * \quad=1 \%$ level of significance 
Table 10

\begin{tabular}{|c|c|c|c|c|c|c|c|c|}
\hline \multicolumn{9}{|c|}{$\begin{array}{l}\text { UNEMPLOYMENT AND LABOR TAXES } \\
\text { (SENSITIVITY ANALYSIS) }\end{array}$} \\
\hline & [1] & [2] & [3] & [4] & [5] & [6] & [7] & [8] \\
\hline $\begin{array}{l}\text { Method of } \\
\text { estimation }\end{array}$ & IV & IV & IV & IV & IV & IV & OLS & OLS \\
\hline Dep.variable & $\Delta \mathbf{u}_{\mathrm{m}}$ & $\Delta u$ & $\Delta \mathbf{u}_{\mathrm{m}}$ & $\Delta \mathbf{u}$ & $\Delta \mathbf{u}$ & $\Delta u$ & $\mathbf{u}$ & $\Delta \mathbf{u}$ \\
\hline Fixed-effects & NO & NO & NO & No & No & NO & YES & No \\
\hline Averaging & 5-YEAR & 5-YEAR & 5-YEAR & 5-YEAR & 5-YEAR & 5-YEAR & 9-YEAR & 9-YEAR \\
\hline $\begin{array}{l}\text { Sample and } \\
\text { country } \\
\text { groups }\end{array}$ & FULL & SPAIN OUT & SPAIN OUT & $\begin{array}{l}\text { BELAND } \\
\text { NETIN } \\
\text { SCAND }\end{array}$ & $\begin{array}{c}\text { UKIN } \\
\text { ANGLOO }\end{array}$ & $\begin{array}{l}\text { UKIN } \\
\text { EURO }\end{array}$ & $\begin{array}{c}\text { AS IN } \\
\text { TABLE } 8\end{array}$ & $\begin{array}{c}\text { AS IN } \\
\text { TABLE } 8\end{array}$ \\
\hline \multirow[t]{2}{*}{$A \tau^{L}$} & 0.39 & 0.33 & 0.23 & 0.44 & 0.51 & 0.23 & $0.26^{\star *}$ & -0.05 \\
\hline & $(0.45)$ & $(0.35)$ & $(0.44)$ & $(0.44)$ & $(0.38)$ & $(0.35)$ & $(0.10)$ & $(0.16)$ \\
\hline \multirow[t]{2}{*}{$E \tau^{L}$} & $1.15^{\star \star \star}$ & $0.48^{* *}$ & $0.96^{\star \star \star}$ & $0.76^{\star \star \star}$ & $0.65^{\star \star \star}$ & $0.62^{\star \star \star}$ & $0.46^{\text {*k* }}$ & $0.31^{\star \star \star}$ \\
\hline & $(0.27)$ & $(0.23)$ & $(0.28)$ & $(0.30)$ & $(0.23)$ & $(0.22)$ & $(0.05)$ & $(0.08)$ \\
\hline \multirow[t]{2}{*}{$S \tau^{L}$} & 0.29 & -0.02 & 0.10 & $0 .+42$ & 0.04 & -0.07 & $-0.31^{\star *}$ & -0.16 \\
\hline & $(0.41)$ & $(0.31)$ & $(0.39)$ & $(0.33)$ & $(0.35)$ & $(0.34)$ & $(0.13)$ & $(0.13)$ \\
\hline \multirow[t]{2}{*}{$\sigma$} & -0.05 & -0.02 & -0.004 & -0.14 & -0.01 & 0.01 & $0.20^{\text {*k* }}$ & $0.07^{\star}$ \\
\hline & $(0.16)$ & $(0.12)$ & $(0.15)$ & $(0.13)$ & $(0.13)$ & $(0.14)$ & $(0.05)$ & $(0.04)$ \\
\hline \#obs & 56 & 52 & 52 & 56 & 56 & 56 & 42 & 42 \\
\hline Adj. $R^{2}$ & 0.35 & 0.01 & 0.23 & -0.08 & 0.09 & 0.13 & 0.90 & 0.38 \\
\hline SEE & 2.46 & 1.83 & 2.29 & 2.28 & 2.08 & 2.04 & 1.13 & 1.72 \\
\hline \multicolumn{9}{|c|}{ P-VALUES FOR: } \\
\hline JB test & 0.17 & 0.04 & 0.77 & 0.10 & 0.28 & 0.28 & 0.84 & 0.001 \\
\hline DFC-LM test & 0.17 & 0.02 & 0.26 & 0.08 & 0.16 & 0.08 & 0.12 & 0.14 \\
\hline
\end{tabular}

Notes:

In all columns with IV estimates: Instruments are right-hand side variables in levels and first differences lagged twice and once respectively;, as well as time dummies.

Column [1]: The dependent variable is one minus the male employment rate. Instruments: Right-hand side variables in levels and first differences lagged twice and once respectively; time dummies.

Columns [2]: Spain left out of the sample. All variables in first differences.

Columns [3]: Spain left out. Dependent variable is one minus the male employment rate. All variables in first differences.

Column [4]: Belgium and Netherlands included in the SCAND group of countries. All variables in first differences.

Column [5]: UK included in the ANGLO group of countries. All variables in first differences.

Column [6]: UK included in the EURO group of countries. All variables in first differences.

Column [7]: 9-year averages. All variables in levels; fixed effects estimation.

Column [8]: 9-year averages. All variables in first differences.

Fixed-effects intercepts and constants not reported. Standard errors in parentheses.

$* \quad=10 \%$ level of significance

$* * \quad=5 \%$ level of significance

$* * * \quad=1 \%$ level of significance 


\section{Table 11}

REAL WAGES AND LABOR TAXES

(5-YEAR AVERAGES)

\begin{tabular}{|c|c|c|c|c|}
\hline & [ 1 ] & [ 2 ] & [3] & [4] \\
\hline $\begin{array}{l}\text { Method of } \\
\text { estimation }\end{array}$ & 2SLS & 2SLS & 2SLS & 2SLS \\
\hline $\begin{array}{l}\text { Dependent } \\
\text { variable }\end{array}$ & $\gamma_{w}$ & $\gamma_{w}$ & $\gamma_{W N}$ & $\gamma_{W N}$ \\
\hline \multirow[t]{2}{*}{$A \Delta \tau^{L}$} & -0.181 & -0.131 & -0.39 & $-0.363^{\star}$ \\
\hline & $(0.263)$ & $(0.186)$ & $(0.238)$ & $(0.211)$ \\
\hline \multirow[t]{2}{*}{$E \cdot \Delta \tau^{L}$} & $0.498^{\star \star \star}$ & $0.490^{\star \star \star}$ & -0.008 & -0.108 \\
\hline & $(0.177)$ & $(0.126)$ & $(0.342)$ & $(0.129)$ \\
\hline \multirow[t]{2}{*}{$S \Delta \tau^{L}$} & 0.197 & 0.095 & -0.215 & 0.042 \\
\hline & $(0.199)$ & $(0.145)$ & $(0.607)$ & $(0.542)$ \\
\hline \multirow[t]{2}{*}{$\Delta \sigma$} & -0.01 & -0.024 & 0.022 & 0.035 \\
\hline & $(0.073)$ & $(0.052)$ & $(0.074)$ & $(0.071)$ \\
\hline \multirow[t]{2}{*}{$g$} & $1.89^{\star \star \star}$ & $0.987^{\star \star \star}$ & 1.03 & 0.465 \\
\hline & $(0.387)$ & $(0.220)$ & $(1.569)$ & $(0.307)$ \\
\hline \multirow[t]{2}{*}{$u$} & - & $-0.20 * * *$ & - & -0.058 \\
\hline & - & $(0.076)$ & - & $(0.074)$ \\
\hline & & & & \\
\hline \#obs & 65 & 65 & 28 & 28 \\
\hline Adj. $R^{2}$ & 0.26 & 0.43 & 0.07 & 0.13 \\
\hline DFC-Lm test & 0.10 & 0.02 & & \\
\hline SEE & 2.46 & 1.74 & 1.49 & 1.42 \\
\hline
\end{tabular}

Notes:

Intercepts not reported. Standard errors in parentheses.

$$
\begin{array}{ll}
* & =10 \% \text { level of significance } \\
* * & =5 \% \text { level of significance } \\
* * * & =1 \% \text { level of significance }
\end{array}
$$

Estimation by 2SLS. The specification for $u$ and $g$ is as in Table 9, column (1), and Table (12), column (2), respectively. The instruments are the current values of the exogenous variables appearing in those equations, including country dummies in the specifications with $u$. See also footnote 30 . 
Table 12

\begin{tabular}{|c|c|c|c|c|c|c|c|}
\hline \multicolumn{8}{|c|}{$\begin{array}{c}\text { GROWTH AND INVESTMENT } \\
\text { (5-YEAR AVERAGES) }\end{array}$} \\
\hline & [1] & [2] & [3] & [4] & [5] & [6] & [7] \\
\hline $\begin{array}{l}\text { Method of } \\
\text { estimation }\end{array}$ & 2SLS & $\begin{array}{c}\text { 2SLS } \\
\text { RHS in } \\
\qquad\end{array}$ & $\begin{array}{c}\text { 2SLS } \\
\text { RHS in } \\
\quad \Delta\end{array}$ & 2SLS & $\begin{array}{l}\text { 2SLS } \\
\text { RHS in } \Delta\end{array}$ & $\begin{array}{c}\text { 2SLS } \\
\text { RHS in } \Delta\end{array}$ & $\begin{array}{c}\text { 2SLS } \\
\text { RHS in } \Delta\end{array}$ \\
\hline Dep.variable & $\mathbf{g}$ & g & g & $\mathrm{i}$ & $\Delta \mathrm{i}$ & gw & gw \\
\hline \multirow[t]{2}{*}{$\tau^{\mathrm{K}}$} & -0.006 & 0.020 & 0.028 & $-0.202^{\star k \star}$ & 0.042 & -0.009 & -0.004 \\
\hline & $(0.014)$ & $(0.050)$ & $(0.051)$ & $(0.044)$ & $(0.092)$ & $(0.053)$ & $(0.056)$ \\
\hline \multirow[t]{2}{*}{$\mathrm{u}$} & $-0.093^{* *}$ & $-0.146^{*}$ & - & $-0.909^{\star \star k \hbar}$ & $-0.744^{\star \star \star}$ & $-0.27^{\text {thx }}$ & - \\
\hline & $(0.043)$ & $(0.086)$ & & $(0.136)$ & $(0.159)$ & $(0.09)$ & \\
\hline \multirow[t]{2}{*}{$\mathrm{u}_{\mathrm{m}}$} & - & - & $-0.150^{* *}$ & - & - & - & $-0.21^{\text {kᄎk }}$ \\
\hline & & & $(0.065)$ & & & & $(0.07)$ \\
\hline \multirow[t]{2}{*}{ Y } & $-3.59^{\text {thk }}$ & $0.241^{*}$ & $0.272^{\star *}$ & -3.547 & -0.190 & $0.30^{\star \star k \star}$ & $0.34^{\star k \star k}$ \\
\hline & $(0.708)$ & $(0.139)$ & $(0.137)$ & $(2.23)$ & $(0.257)$ & $(0.12)$ & $(0.13)$ \\
\hline \multirow{2}{*}{ SCHOOL } & 1.62 & 3.94 & 5.46 & $14.76^{\text {thk }}$ & 7.51 & -0.91 & 1.48 \\
\hline & $(1.082)$ & (3.09) & (3.29) & $(3.41)$ & (5.72) & (3.37) & (3.63) \\
\hline \#obs & 70 & 56 & 56 & 70 & 56 & 56 & 56 \\
\hline Adj. $R^{2}$ & 0.45 & 0.10 & 0.10 & 0.54 & 0.26 & 0.17 & 0.04 \\
\hline SEE & 1.11 & 1.15 & 1.16 & 3.50 & 2.12 & 1.19 & 1.25 \\
\hline \multicolumn{8}{|c|}{ P-VALUES FOR: } \\
\hline JB test & 0.0001 & 0.0003 & 0.003 & 0.005 & 0.0002 & 0.001 & 0.001 \\
\hline DFC-LM test & 0.0001 & 0.09 & 0.09 & 0.004 & 0.02 & 0.03 & 0.03 \\
\hline Hausman-LM & & 0.78 & & & & & \\
\hline
\end{tabular}

Notes: Columns [1], [4] : All RHS variables in levels. Instruments: Contemporaneous values of all the exogenous variables - that is excluding $u$ and $u_{t-1}$ - listed in this Table and in Table 9, including country dummies.

Columns [2], [3], [5] - [7]: All RHS variables in first differences. Instruments: All the exogenous variables in this Table and Table 9, expressed in first differences lagged once and in levels lagged twice; unemployment in first differences lagged once and in levels lagged twice; time dummies.

Intercepts not reported. Standard errors in parentheses.

$* \quad=10 \%$ level of significance

$* * \quad=5 \%$ level of significance

$* * * \quad=1 \%$ level of significance 
Table 13

\begin{tabular}{|c|c|c|c|c|c|c|c|}
\hline \multicolumn{8}{|c|}{$\begin{array}{c}\text { GROWTH AND INVESTMENT } \\
\text { SENSITIVITY ANALYSIS }\end{array}$} \\
\hline & [1] & [2] & [3] & [4] & [5] & [6] & [7] \\
\hline $\begin{array}{l}\text { Method of } \\
\text { estimation } \\
\end{array}$ & 2SLS & $\begin{array}{c}2 \mathrm{SLS} \\
\text { RHS in } \Delta\end{array}$ & $\begin{array}{c}\text { 2SLS } \\
\text { RHS in } \Delta\end{array}$ & $\begin{array}{c}2 \mathrm{SLS} \\
\text { RHS in } \Delta\end{array}$ & 2SLS & $\begin{array}{c}\text { 2SLS } \\
\text { RHS in } \Delta\end{array}$ & $\begin{array}{c}2 \mathrm{SLS} \\
\text { RHS in } \Delta\end{array}$ \\
\hline Dep.variable & g & $\mathrm{g}$ & $\mathrm{g}$ & g & $g_{k \| 1}$ & $\mathrm{~g}$ & $\Delta \mathrm{i}$ \\
\hline Sample & FULL & FULL & SPAI N OUT & SPAIN OUT & FULL & FULL & FULL \\
\hline Averaging & 9-YEAR & 9-YEAR & 5-YEAR & 5-YEAR & 5-YEAR & 5-YEAR & 5-YEAR \\
\hline \multirow[t]{2}{*}{$\tau^{\mathrm{K}}$} & -0.009 & $-0.09^{\star \star}$ & 0.033 & 0.039 & - & 0.012 & 0.118 \\
\hline & $(0.012)$ & $(0.04)$ & $(0.047)$ & $(0.048)$ & & $(0.072)$ & $(0.146)$ \\
\hline \multirow[t]{2}{*}{$\mathrm{u}$} & $-0.11^{* *}$ & $-0.26^{*}$ & -0.095 & - & - & - & - \\
\hline & $(0.05)$ & $(0.14)$ & $(0.10)$ & & & & \\
\hline & & & & & & & \\
\hline \multirow[t]{2}{*}{$\mathrm{u}_{\mathrm{m}}$} & - & - & - & $-0.138^{* *}$ & - & - & - \\
\hline & & & & $(0.070)$ & & & \\
\hline & & & & & & & \\
\hline \multirow[t]{2}{*}{$\mathrm{Y}$} & $-4.10^{* * *}$ & $0.34^{\star \star \star}$ & $0.27^{*}$ & $0.28^{\star *}$ & - & 0.221 & -0.474 \\
\hline & $(0.82)$ & $(0.09)$ & $(0.14)$ & $(0.14)$ & & $(1.68)$ & $(0.341)$ \\
\hline \multirow[t]{2}{*}{ SCHOOL } & $2.33^{*}$ & -1.00 & 1.82 & 3.01 & - & 5.11 & 12.99 \\
\hline & $(1.24)$ & $(1.93)$ & (3.18) & (3.29) & & $(4.08)$ & $(8.28)$ \\
\hline \multirow{2}{*}{$g$} & - & - & - & - & $0.82^{* \star}$ & - & - \\
\hline & & & & & $(0.37)$ & & \\
\hline & & & & & & & \\
\hline \multirow[t]{2}{*}{$g_{w}$} & - & - & - & - & $0.72^{\star \star \star}$ & - & - \\
\hline & & & & & $(0.19)$ & & \\
\hline & & & & & & & \\
\hline \multirow[t]{2}{*}{$\mathrm{A} \tau^{\mathrm{L}}$} & - & - & - & - & - & 0.02 & 0.25 \\
\hline & & & & & & $(0.224)$ & $(0.455)$ \\
\hline & & & & & & & \\
\hline \multirow[t]{2}{*}{$\mathrm{E} \tau^{\mathrm{L}}$} & - & - & - & - & - & -0.10 & -0.36 \\
\hline & & & & & & $(0.161)$ & $(0.327)$ \\
\hline & & & & & & & \\
\hline \multirow[t]{2}{*}{$S \tau^{\mathrm{L}}$} & - & - & - & - & - & -0.11 & -0.10 \\
\hline & & & & & & $(0.244)$ & $(0.495)$ \\
\hline & & & & & & & \\
\hline \multirow[t]{2}{*}{$\sigma$} & - & - & - & - & - & 0.056 & -0.06 \\
\hline & & & & & & $(0.072)$ & $(0.145)$ \\
\hline & & & & & & & \\
\hline \#obs & 42 & 42 & 52 & 52 & 65 & 56 & 56 \\
\hline Adj. $R^{2}$ & 0.58 & 0.40 & 0.09 & 0.03 & 0.41 & 0.01 & -0.02 \\
\hline SEE & 0.96 & 1.14 & 1.08 & 1.10 & 2.28 & 1.25 & 2.53 \\
\hline \multicolumn{8}{|c|}{ P-VALUES FOR: } \\
\hline JB test & 0.01 & 0.02 & 0.0001 & 0.0001 & 0.004 & 0.0003 & 0.0002 \\
\hline DFC-LM test & 0.04 & 0.01 & 0.04 & 0.04 & 0.005 & 0.09 & 0.02 \\
\hline
\end{tabular}




\section{Notes to Table 13:}

Column [1]: All variables in levels. Instruments: Contemporaneous values of all the exogenous variables in this Table, that is excluding $u$, including country dummies.

Column [2]: All RHS variables in first differences. Instruments: Contemporaneous values of all the exogenous variables in first differences, that is excluding $\Delta u$, and including labor taxes and replacement rates. Differenced variables for the first nine period are computed as described in footnote 22.

Columns [3]-[4] : All RHS variables in differences. Instruments: All RHS variables in this table, expressed in levels and first differences lagged twice and once respectively; time dummies; unemployment lagged once in differences and twice in levels. Unemployment replaced by one minus the male employment rate (in percentage points) in columns and [4].

Column [5]: Growth of gross real wages instrumented as from column [1] in table 11 and growth of percapita GDP as from column [1] in Table 12 .

Columns [6] - [7]: All RHS variables in first differences. Instruments: All the exogenous variables in this Table, expressed in first differences lagged once and in levels lagged twice; unemployment in first differences lagged once and in levels lagged twice; time dummies.

Intercepts not reported. Standard errors in parentheses.

$* \quad=10 \%$ level of significance

$* * \quad=5 \%$ level of significance

$* * * \quad=1 \%$ level of significance 
Figure 1: Growth and unemployment

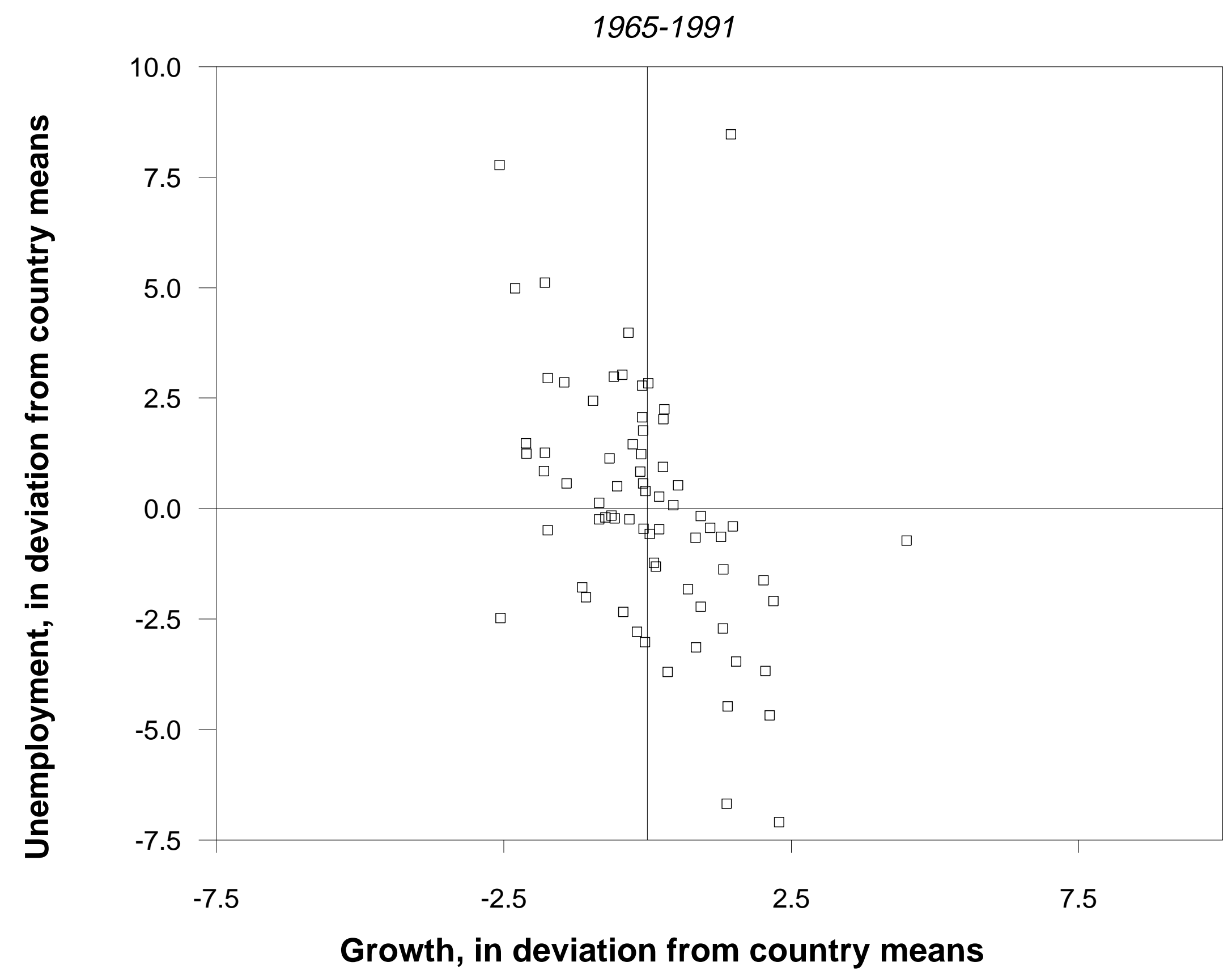


Figure 2: Labor taxes and unemployment in continental Europe

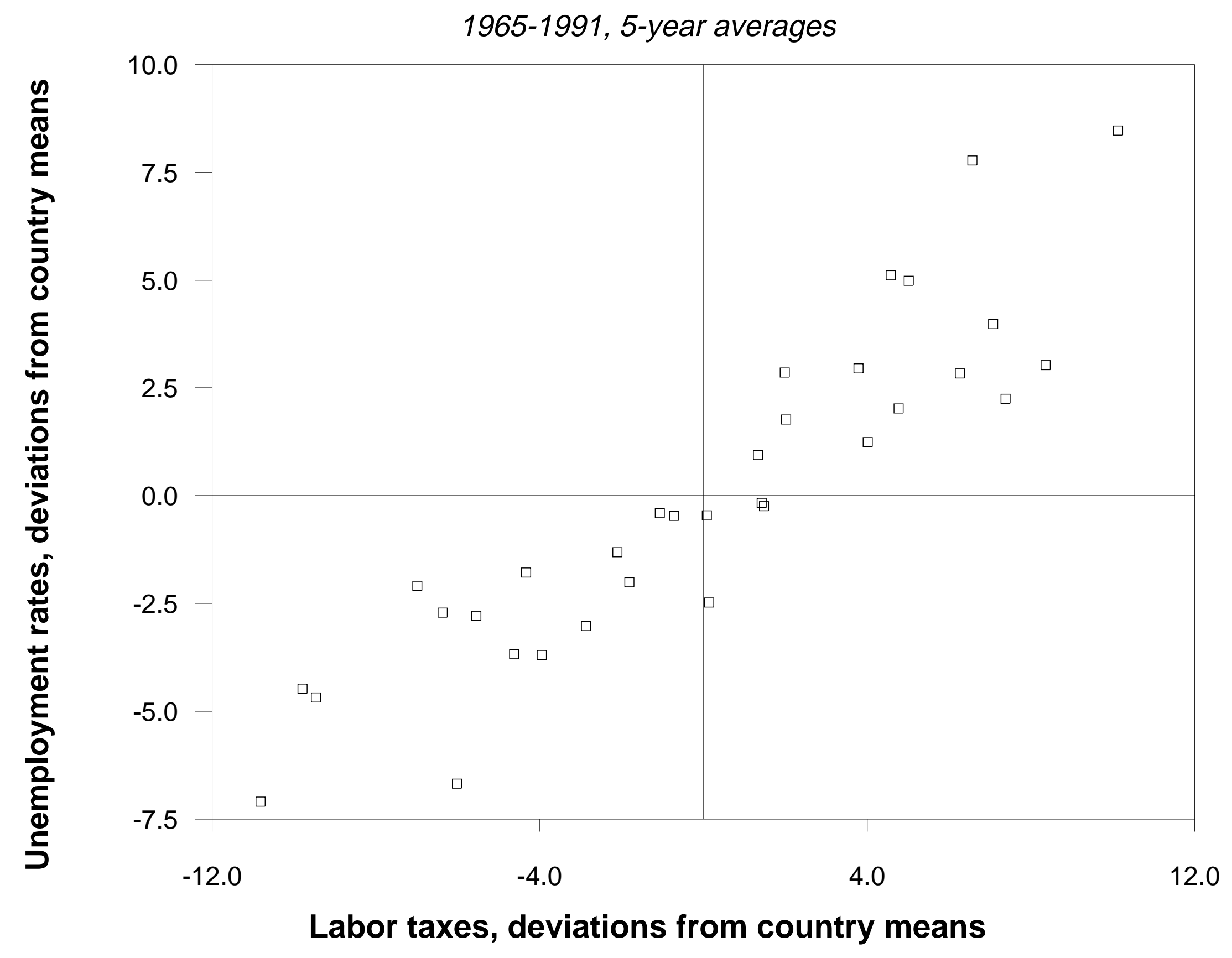


Figure 3: Labor taxes and unemployment outside continental Europe

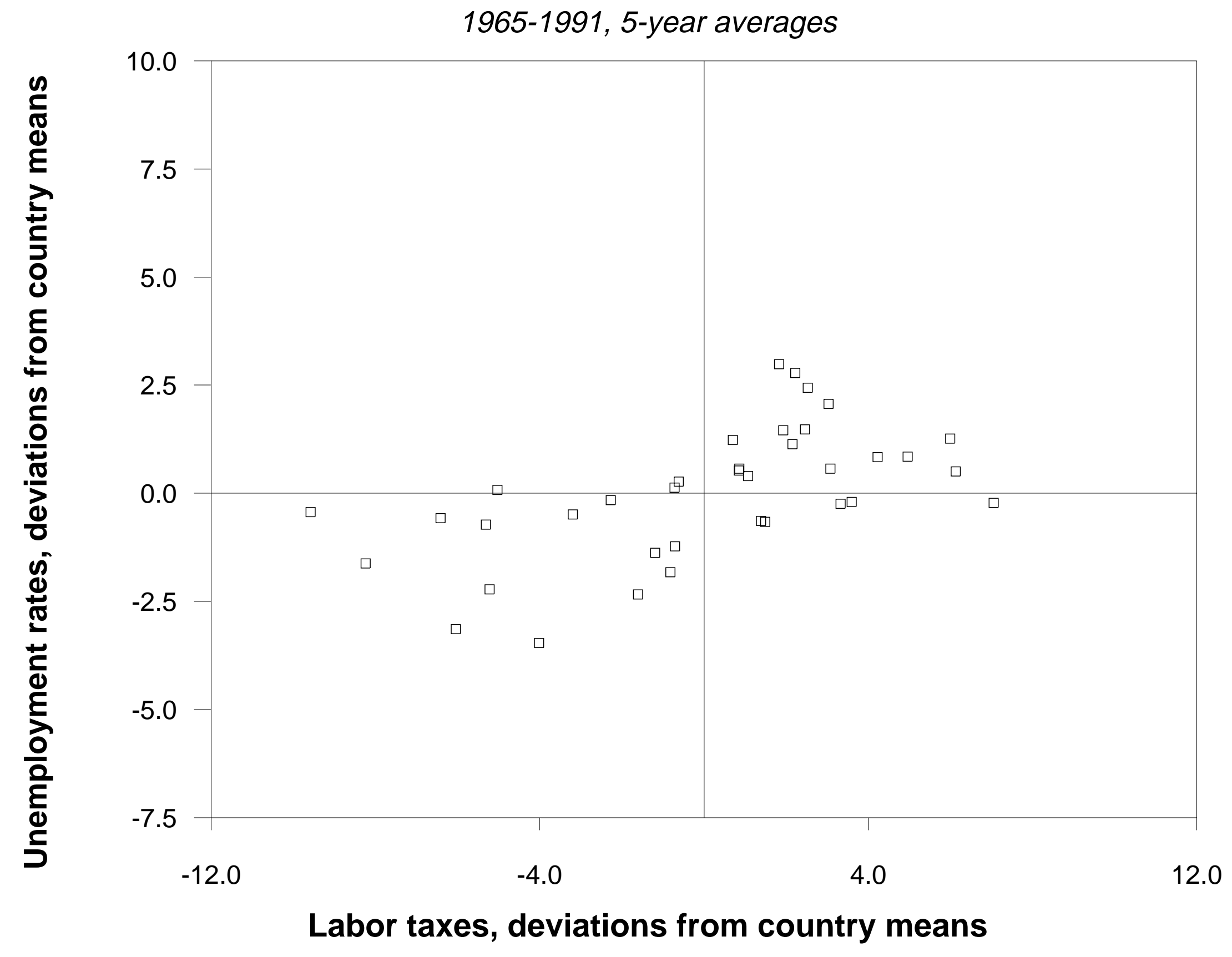

